\title{
Toxoplasma ERK7 defends the apical complex from premature degradation
}

William J. O'Shaughnessy ${ }^{1, \dagger}$, Xiaoyu Hu, ${ }^{1, \dagger}$, Sarah Ana Henriquez ${ }^{1}$, Michael L. Reese ${ }^{1,2, *}$

${ }^{1}$ Department of Pharmacology, University of Texas, Southwestern Medical Center, Dallas, TX USA

${ }^{2}$ Department of Biochemistry, University of Texas, Southwestern Medical Center, Dallas, TX USA

${ }^{\dagger}$ W.J.S. and X.H. contributed equally to this work.

*Address correspondence to Michael L. Reese, michael.reese@utsouthwestern.edu

10 ORCIDs:

Michael Reese: 0000-0001-9401-9594

William O'Shaughnessy: 0000-0002-6868-2648

Sarah Ana Henriquez: 0000-0001-8574-2748

15 Keywords: Kinase, cilium, apical complex, microtubule, ubiquitin-mediated degradation

Short title: Toxoplasma ERK7 regulates cytoskeleton turnover 
20 Apicomplexan parasites such as Plasmodium and Toxoplasma replicate by forming daughter cells within an intact mother cell, creating additional challenges to ensuring fidelity of division. Critical to these parasites' infectivity is an intricate cytoskeleton structure called the apical complex. Before the daughter apical complex can be inserted into the plasma membrane, the maternal material must be turned over. We previously identified the kinase ERK7 as required for the maturation of the apical

25 complex in Toxoplasma gondii. Here we define the Toxoplasma ERK7 interactome, and identify a putative E3 ligase, CSAR1, as the downstream effector responsible for the phenotype. Genetic disruption of CSAR1 fully suppresses loss of the apical complex upon ERK7 knockdown. Furthermore, we show that CSAR1 is normally responsible for turnover of maternal cytoskeleton during cytokinesis, and that its aberrant function is driven by a mislocalization from the parasite residual body to the

30 maternal and daughter apical complexes. These data identify a protein homeostasis pathway critical for Toxoplasma replication and fitness and suggest an unappreciated role for the parasite residual body in compartmentalizing processes that threaten the fidelity of parasite development. 


\section{Introduction}

Cellular division is the fundamental biological process of replicating both the genetic material and

35 the cellular structures required for viability. In most cells, successful division requires a careful balance of the creation and destruction of specific structures, and both biogenesis and turnover are highly regulated processes. Apicomplexan parasites, which include the causative agents of malaria, cryptosporidiosis, and toxoplasmosis, use a variety of extraordinary replication paradigms in which a varied number of daughter cells are fully formed within a mature mother parasite (1-3). In these organisms, organellar biogenesis is tightly temporally coupled to the cell cycle to ensure correct packaging into daughters $(4,5)$. In addition, maternal material, such as cytoskeleton, must be turned over to make room for the daughter cells' components (6-9).

Asexual division in the parasite Toxoplasma gondii occurs through endodyogeny, in which two daughter cells fully form within a mother cell (Figure 1A). By maintaining an intact mother cell until

45 cytokinesis, endodyogeny allows the parasite to remain invasive until the final steps in division. During cytokinesis, discarded maternal organelles and cytoplasm are packaged into a poorly understood organelle called the residual body $(10-12,4)$ (Figure $1 \mathrm{~A})$, through which individual parasites remain connected and share cytosolic material $(13,14)$. While major inroads have been made in our understanding of centrosome division $(15,16)$, organellar replication $(5,14,17,18)$, and cell cycle

50 control (19-21), the process of cytokinesis has been largely unstudied in Apicomplexa.

Central to apicomplexan parasitism is a cytoskeletal structure called the apical complex, for which this phylum of parasites was named. This structure organizes specialized secretory organelles and forms the core of the parasite invasion machinery. The organizing core of the apical complex is called the conoid, and is conserved throughout Apicomplexa $(22,23)$, as well as outside of Apicomplexa in

55 early-branching Alveolates $(24,25)$, suggesting a truly ancient origin. In Toxoplasma, the conoid is formed from unusual tubulin fibers that do not form closed tubes (26) and is thought to have evolved from a more typical eukaryotic cilium, as it contains orthologs of cilium-associated proteins (27-31). The conoid is the structure through which secretion is thought to occur $(32,33)$, and appears essential 
for the initiation of parasite actin-based motility and host cell invasion (14, 34).

60 We recently identified the MAP kinase ERK7 as required for the development of a functional conoid in Toxoplasma (35). Parasites in which ERK7 is inducibly degraded using an auxin-inducible degron (AID) (36) lose their conoids late in daughter cell assembly (Figure 1B). ERK7 localizes to the apical tip of both mature and developing daughter parasites, and loss of scaffolds required for this apical targeting phenocopies the degradation of $\operatorname{ERK} 7(37,38)$. Furthermore, ERK7 kinase activity is

65 required for its essential functions (35). Together, these data led us to the hypothesis that ERK7 phosphorylates one or more proteins that are essential to the assembly and/or maturation of the developing conoid (Figure 1B).

ERK7 is the earliest branching MAP kinase in eukaryotes, and is found in all organisms with ciliated cells $(35,39)$. However, very few ERK7 interacting partners or substrates have been identified

70 and validated in any organism. In this study, we combined proximity biotinylation (40) and yeast-twohybrid (41) to describe the Toxoplasma ERK7 interactome. Among the interacting proteins, we identified a number of potential ERK7 partners with potential roles in the parasite cytoskeleton and in intracellular trafficking. Intriguingly, we identified a parasite-specific predicted RING-family ubiquitin E3 ligase that mislocalizes to the apical cap and conoid upon ERK7 degradation. We generated

75 knockouts for the E3 ligase, and found that these parasites were unable to turnover their maternal apical complex and microtubule cytoskeleton. We therefore named the protein CSAR1 (ㅌytoskeleton Salvaging RING family member 1). Most importantly, knockout of CSAR1 completely suppressed the loss of ERK7 function, allowing the maturation of functional conoids even when ERK7 had been degraded. These findings demonstrate that protein degradation is a critical component of the

80 functional maturation of the apical complex, and that ERK7 is an essential regulator of this process.

\section{Results}

BiolD and Yeast-two-Hybrid reveal a diverse set of interacting partners for Toxoplasma ERK7

We had previously identified apical cap protein 9 (AC9) as an essential regulatory scaffold that 
was required to recruit ERK7 to the parasite apical cap and thus for the formation of a functional apical

85 complex (37). Moreover, we had demonstrated that ERK7 kinase activity is required for its function (35). Taken together, these data suggested that delineating the ERK7 interactome would identify other upstream regulators and the downstream substrates through which ERK7 mediates its function in ensuring maturation of the Toxoplasma apical complex. To this end we combined two orthogonal methods to identify Toxoplasma proteins that interact with ERK7: yeast-two-hybrid (41) and proximity

90 biotinylation (42). Proximity biotinylation, or BiolD, uses a promiscuous biotin ligase to biotinylate proteins within $\sim 10 \mathrm{~nm}$ of the bait (43), and is thus able to report on direct and indirect interactions within larger complexes as well as transient interactions, such as enzyme:substrate pairs. Yeast-twohybrid relies on heterologous expression of a cDNA library in S. cerevisiae and probes only proteins that directly interact with the bait.

95 To perform BiolD, we used a CRISPR-assisted homologous recombination strategy to Cterminally tag the endogenous copy of ERK7 with a 3xHA-BiolD2 (44). We also created a control strain in which the ERK7 promoter drives the expression of mVenus-3xHA-BiolD2. We infected human foreskin fibroblasts (HFF) with each of these strains, and grew them for $36 \mathrm{~h}$ in the presence of 150 $\mu \mathrm{m}$ biotin. Parasites were collected, lysed in RIPA buffer, and biotinylated proteins enriched by 100 incubation with streptavidin resin. Proteins were eluted from the resin and analyzed by liquid chromatography-tandem mass spectrometry. Data from 3 replicates of each the ERK7 and control samples were compared and proteins with an average $>2$-fold enrichment over the control were considered candidate interactors (Tables 1,2, Supplemental Data S1). We also included candidates identified in our data set that had been previously identified in a previous conoid proteome (45), but for

105 which no localization data were available. Our BiolD data appeared of high quality, as the top candidates included many known components of the apical cap and IMC, including both AC9 and AC10, which form a complex that recruits ERK7 to the apical cap (37).

For yeast-two-hybrid, the full-length Toxoplasma ERK7 sequence (residues 2-692) was used as bait to probe a cDNA library derived from RH tachyzoites. From 267 individual clones, we identified 21 
110 distinct candidate interactors (Tables 1,2 and Supplemental Data S1), 13 of which we consider of highest quality based on the number of unique clones recovered for each. Notably, 8 of our yeast-twohybrid hits were also identified by BiolD, indicating good agreement between the two methods. Candidate ERK7 interactors were enriched in both known and newly identified proteins comprising IMC cytoskeleton, potentially involved in protein/membrane trafficking, and proteins that, like ERK7,

115 concentrate at the apical end of the parasite during daughter budding (Tables 1,2 and Supplemental Figure 1).

One candidate interactor stood out for the stark difference in its localization upon ERK7 degradation (Figure 2). We found that $\mathrm{TG}^{*}{ }_{-} 315950$ had very low signal in mature parasites and at early stages of division (Figure 2A). However, we observed high punctate signal restricted to maternal 120 cytosol late in the budding process. The high signal continued through cytokinesis, during which $\mathrm{TG}^{*} 315950$ appears restricted to the residual body (Figure 2A). Intriguingly, we observed very little colocalization between TG*_315950 and ERK7 (Figure 2C). Thus, TG*_315950 appears to be involved late in the budding process, though it is normally concentrated at the residual body. Unexpectedly, in parasites grown in IAA to induce ERK7 degradation, we found that TG* 315950

125 concentrates at the daughter apical caps and conoids late in the budding process (Figure 2B). Thus loss of ERK7 causes a mislocalization of $\mathrm{TG}^{*}{ }^{*} 315950$ protein.

Loss of CSAR1 allows parasites to complete the lytic cycle without ERK7, but is required for full parasite fitness

TG*_315950 encodes a 1822 residue protein with a predicted RING domain at its C-terminus,

130 suggesting that it functions as an E3 Ub ligase. Given that TG*_315950 mislocalizes to the apical caps of budding daughters upon ERK $7^{\text {AID }}$ degradation, we reasoned that TG*_315950 may have aberrant function of its E3 ligase activity in which it inappropriately targets daughter conoids for degradation when ERK7 is not correctly localized to the daughter buds. For its apparent role in turnover of the parasite cytoskeleton, we have named TG*_315950 CSAR1 (ㅌytoskeleton Salvaging RING family

135 member 1). If CSAR1 does indeed mediate the loss of the daughter conoids upon ERK7 loss-of- 
function, disruption of CSAR1 activity should rescue the ERK7 conoid phenotype. To address this question, we attempted to create a strain in which both ERK7 and CSAR1 were tagged with AID and therefore could be simultaneously inducibly degraded. We were unable to visualize any $3 x \mathrm{HA}$ signal of CSAR1 C-terminally tagged with AID-3xHA, and the parasites had a markedly reduced fitness,

140 suggesting that we had produced either a hypomorph or null allele of CSAR1. We therefore used CRISPR/Cas9-assisted homologous recombination to replace the CSAR1 coding sequence with an HXGPRT selection cassette in the background of the ERK7 ${ }^{A I D}$ (eGFP-tubulin) strain. This $\mathrm{RH} \Delta \operatorname{csar1}$ (ERK7 ${ }^{\mathrm{AID}} / \mathrm{eGFP}$-tubulin; hereafter, referred to as $\Delta c s a r 1$ ) strain fully reproduced the phenotype of the CSAR1 ${ }^{\text {AID }}$ strain. Importantly, $\Delta c s a r 1$ had no effect on auxin-mediated degradation of

145 ERK7 protein (Figure 3A). We used a plaque assay to compare gross parasite fitness through the lytic cycle (Figure 3B,C). As expected, we observed no plaques from ERK7 $7^{A I D}$ parasites grown in the presence of IAA. Strikingly, $\Delta c s a r 1$ parasites showed equivalent plaque efficiency whether or not ERK7 had been degraded (Figure 3B). In addition, the plaque efficiency was not significantly different from that of the parental ERK7 ${ }^{\text {AID }}$ strain grown in the absence of IAA. These data demonstrate that the

150 loss of CSAR1 suppresses the essentiality of ERK7 in the Toxoplasma lytic cycle.

While loss of CSAR1 did not reduce the plaquing efficiency as compared with the ERK7 ${ }^{\text {AID }}$ parental strain, the plaque sizes were significantly smaller (Figure $3 \mathrm{C}$ ). In the absence of IAA, $\Delta$ csar1 parasites produced plaques $\sim 70 \%$ the size of the parental ERK7 ${ }^{\text {AID }}$ strain. In the presence of IAA, $\Delta$ csar1 parasites produced plaques only $\sim 15 \%$ the size of the parental strain in the -IAA condition,

155 suggesting that degradation of ERK7 reduces fitness in these parasites, which may synergize with the loss of fitness caused by deletion of $\Delta c s a r 1$. The plaque number and size simultaneously informs on every step in the Toxoplasma lytic cycle: invasion, replication, and egress. We therefore tested the $\Delta c s a r 1$ fitness for each of these steps.

To test invasion efficiency, we allowed $1 \times 10^{6}$ parasites of either $\Delta$ csar1 or parental ERK $7^{\text {AID }}$ strain 160 (grown \pm IAA for $>12$ hours prior to experiment) to invade for 1 hour before fixation. Consistent with our previously published observations $(35,37)$, degradation of ERK7 blocked attachment and invasion in 
the ERK7 $7^{\text {AID/AA }}$ parasites (Figure 3D). On the other hand, while $\Delta$ csar1 parasites invaded less efficiently than the parental ERK $7^{\text {AID }}$, their invasion was unaffected by growth in IAA (Figure 3D). Thus CSAR1 is required for the ERK7 phenotype on invasion.

165 We next tested whether deletion of CSAR1 altered the efficiency of parasite egress from an infected cell and the parasites' motility, once extracellular. Parasites were allowed to invade fibroblasts for $4 \mathrm{~h}$ and then grown for 24-36 $\mathrm{h}$ in the presence or absence of IAA. Egress was induced by incubation with calcium ionophore for $1 \mathrm{~min}$ and parasites were immediately fixed. We quantified efficiency of egress by two metrics: by scoring whether the parasite vacuole had ruptured, using GRA1

170 as a marker for an intact vacuole (Figure 3E). As expected, all vacuoles of the ERK7 ${ }^{\text {AID }}$ strain had egressed within $1 \mathrm{~min}$ when grown in the absence of IAA, but ERK7 $7^{\text {AID/AA }}$ parasites exhibited a complete block in egress (Figure $3 \mathrm{E}$ ). The $\Delta$ csar1 parasites, however, readily egressed even when grown in IAA (Figure 3D), demonstrating that loss of CSAR1 rescues the ERK7 egress phenotype, as well. However, we noted that $\Delta c s a r 1$ parasites appeared to have a modest delay in egress, as $\sim 5 \%$ of

175 vacuoles remained intact during the treatment with ionophore, regardless of treatment with IAA. However, while this slight delay in egress was reproducible, it was not statistically significant $(p>$ 0.05).

As a mild defect in egress was unlikely to be responsible for the reduction in plaque size we observed in the $\Delta c s a r 1$ parasites, we reasoned that replication rate may be affected, as well. We

180 therefore allowed parasites of both strains to invade for $4 \mathrm{~h}$ before changing the media to either \pm IAA for $24 \mathrm{~h}$ growth. We stained parasites Parasites were stained with anti-IMC1 antibody and Hoescht and quantified the number of parasites in each vacuole (Figure 3F,G). Consistent with their smaller plaques, we observed that $\Delta c s a r 1$ parasites had a substantial reduction in their replication rate as compared with the ERK7 ${ }^{\mathrm{AID}}$ parental and this phenotype was further exacerbated by growth in IAA,

185 indicating loss of ERK7 still reduces fitness in these parasites. Therefore, loss of CSAR1 suppresses the essentiality of ERK7 at the cost of efficient parasite replication. 


\section{CSAR1 is required for recycling of maternal cytoskeleton during cytokinesis}

To examine if there were any gross ultrastructural defects in the Toxoplasma cellular structure in

190 the $\Delta c s a r 1$ parasites, we compared the parental ERK $7^{\text {AID }}$ and $\Delta c s a r 1$ parasites by fluorescence microscopy. Parasites were grown in fibroblasts for 18-24 h, fixed, and microtubule structures visualized with GFP-tubulin. We also stained with antibodies against ERK7 and IMC1, which we used as a marker for the inner membrane complex that outlines each parasite and growing buds (Figure $4 A, B)$. Both ERK7 $7^{\text {IID }}$ and $\Delta c s a r 1$ parasites appear normal. However, $\Delta c s a r 1$ vacuoles retain the apical

195 complex and microtubule cytoskeleton in the parasite residual body after each replication. We observed n-1 retained maternal cytoskeletons per parasite in each $\Delta$ csar1 vacuole (e.g. 1 in 2-pack, 3 in a 4-pack). Thus CSAR1 is essential for turnover and salvaging of these microtubule structures.

\section{Loss of CSAR1 leads to increased plasticity in daughter cell number during Toxoplasma division}

Toxoplasma replicates by endodyogeny, in which exactly two daughter buds mature within the

200 maternal cell (Figure 1). Normal division involves the generation of exactly two daughter buds. however, in rare cases $(<1 \%)$, wild-type Toxoplasma division can result in 3 or more buds $(17,46)$. In imaging cells to examine replication, we noticed that $\Delta c s a r 1$ parasites appeared to have an unusually high number of aberrant budding events (Figure 3G, Figure 5A). To compare the extent of non-binary parasite budding in $\Delta c s a r 1$ versus the parental strain, we allowed parasites to invade for $2 \mathrm{~h}$, washed

205 off extracellular parasites, and allowed parasites to grow for $6 \mathrm{~h}$ at $37^{\circ} \mathrm{C}$ before being fixed and stained for imaging. To test the effect of ERK7 degradation on aberrant parasite budding, parasites were grown in the presence or absence of IAA. We quantified the number of buds per parasite for each condition (Figure 5B). While we did not observe aberrant dividing ERK $7^{\text {AID }}$ parasites, a remarkable $10 \pm 1 \%$ of $\Delta c s a r 1$ parasites had $>2$ buds per division (Figure $5 \mathrm{~B}$ ). This phenotype was not further

210 exacerbated by growth in IAA, indicating loss of ERK7 does not affect the daughter-count during budding.

A previous analysis of rare non-binary division in wild-type Toxoplasma indicated that the majority of parasites resulting from non-binary division were viable (46). Because the maternal cytoskeleton is 
retained in the residual body of $\Delta c s a r 1$ parasites (Figure 4), we can unambiguously identify parasites

215 that have divided exactly once since infection. We used this fact to test whether non-binary division events produced viable parasites in $\Delta$ csar1. We defined viable parasites as objects that showed appropriate signal for each GFP-tubulin, IMC1, and DAPI. After a single round of division, we found that only $1 \pm 0.7 \%$ vacuoles contained more than 2 mature parasites, which is substantially lower than expected by the $\sim 10 \%$ of non-binary buds we observe in actively dividing parasites. Instead, we

220 observed that many vacuoles contained what appeared to be malformed parasites in their residual bodies, lacking either a complete nucleus, inner membrane complex, or microtubule cytoskeleton (Figure 5C). Thus it appears that, unlike what has been reported for wild-type parasites (46), many of the non-binary division events in $\Delta c s a r 1$ produce non-viable progeny.

Normally, Toxoplasma divide to form a rosette within a vacuole, such that the apical ends are 225 oriented away from the residual body at the vacuole's center. Furthermore, normal parasite division is synchronized within a vacuole. This synchrony has been attributed to active trafficking of cytosolic components between parasites along a network of actin filaments that is organized within the residual body $(13,14)$. Given that CSAR1 localizes to the residual body (Figure 2) and its disruption causes aberrant division (Figure 5A-C), we reasoned that disruption of CSAR1 may also affect vacuole

230 organization and synchrony of division. To this end, we analyzed the images we had used to quantify parasite replication for these phenotypes. $90 \pm 5 \%$ of $E R K 7^{A I D}$ vacuoles showed typical rosette arrangement regardless of IAA treatment and $90 \pm 10 \%$ these vacuoles were dividing synchronously (Figure $5 \mathrm{D}-\mathrm{F}$ ). In contrast, $94 \pm 1 \%$ of $\Delta c s a r 1$ vacuoles had lost the rosette organization, though degradation of ERK7 with addition of IAA did not further impact the phenotype (Figure 5E,F). Similarly,

235 while all parental vacuoles were dividing synchronously, we observed that $40 \pm 10 \% \Delta$ csar1 vacuoles contained parasites at markedly different points in the cell cycle (Figure 5E,F).

In absence of ERK7, CSAR1 mediates degradation of maturing daughter conoids

Disruption of CSAR1 enabled ERK7 $7^{\text {AID }}$ parasites to escape the block in the lytic cycle due to ERK7 degradation (Figure 3B). Loss of CSAR1 also blocks turnover of maternal apical complex and 
240 microtubule cytoskeleton after division (Figure 4) and CSAR1 mislocalizes to the daughter apical caps upon ERK7 degradation (Figure 2B). Taken together with its predicted function as an E3 ubiquitin ligase, these data suggested that CSAR1 was responsible for the loss of daughter conoids in parasites in which ERK7 had been degraded. We used confocal microscopy to assess this model. Consistent with published data (35), we observed normal conoids in ERK7 AID parasites, though the 245 conoid was lost in these parasites upon ERK7 degradation (Figure 6B). In the $\Delta c s a r 1$ parasites, however, not only is does the maternal cytoskeleton build up in the residual body after replication (Figure 6C), but we also observe strong tubulin puncta in all parasites after treatment with IAA, consistent with preservation of the conoid (Figure 6D).

To better understand the timing of conoid loss upon ERK7 degradation, we used video

250 microscopy of eGFP-tubulin signal to follow parasite budding and cytokinesis in living ERK7 ${ }^{\text {AID }}$ and $\Delta$ csar1 parasites grown in IAA. In ERK7 ${ }^{\mathrm{AID}}$ parasites grown in IAA, we observed that the maternal conoid is lost $78 \pm 47$ min before the initiation of cytokinesis (Figure 6E, Supplemental Movie 1), and the daughter conoid signal is lost $31 \pm 12$ min later ( $n=17$ parasites). The loss of the maternal conoid in the first cycle of division after ERK7 degradation is inconsistent with our original model that ERK7 is

255 required for assembly of a functional conoid (35), and instead suggests that the mature conoid is degraded in these parasites. Consistent the preservation of the conoid we observe by confocal imaging (Figure 6B), we see no effect on the GFP-tubulin conoid signal during division of $\Delta$ csar1 parasites grown in IAA (Figure 6F, Supplemental Movie 1).

To test whether there are obvious changes in the apical complex ultrastructure in $\Delta c s a r 1$ parasites 260 as compared to the parental ERK7 ${ }^{\mathrm{AID}}$ strain, we visualized detergent-extracted parasite cytoskeleton ghosts by transmission electron microscopy (Figure 7). As expected, the parasite cytoskeleton appears normal in ERK7 ${ }^{A I D}$ parasites untreated with IAA (Figure 7A), but the conoid is completely missing after growth in IAA (Figure 7B). In $\Delta$ csar1 parasites, all detergent-stable cytoskeleton structures appeared normal, regardless of whether ERK7 had been degraded with IAA (Figure 7C,D).

265 Thus deletion of $\Delta c s a r 1$ does not appear to negatively impact apical complex assembly or function, 
and appears to protect the overall structure of the conoid when ERK7 has been degraded (Figure 8).

\section{Discussion}

We have delineated the protein interactome for Toxoplasma ERK7. In other organisms, ERK7 orthologs in have been associated with the regulation of variety of cellular processes, including

270 ciliogenesis (47-49), protein trafficking and signaling (50-53), and autophagy (54). Because ERK7 appears to be found exclusively yet consistently in eukaryotes with ciliated cells $(35,39)$, it seems likely that its role in cilia biogenesis and maintenance is a primary conserved function. Consistent with this idea, our ERK7 interactome is enriched in proteins localizing to the parasite cytoskeleton and apical complex (Tables 1,2). Intriguingly, among the putative interactors we identified for Toxoplasma

275 include the autophagy processing enzyme ATG4 and a number of proteins that appear to localize to the parasite endolysosomal trafficking system (Tables 1,2, Supplemental Table S1, Supplemental Figures SX-Y). These findings suggest that other reported functions for ERK7 may be present in Toxoplasma, as well. Defining the relationship between ERK7 and these pathways in Toxoplasma and other organisms will determine whether there is, indeed, a core conserved ERK7 signaling pathway.

280 We originally identified ERK7 as essential to the maturation of the Toxoplasma apical complex (35), and initiated this study to determine the downstream effectors that potentiate this function. We identified a putative RING-family E3 ligase, CSAR1, as this molecule. While we had originally envisioned the ERK7 loss-of-function phenotype as a loss of a positive regulation, we found that CSAR1 appears to function aberrantly upon ERK $7^{\text {AID }}$ degradation. We found that CSAR1 is required

285 for the turnover of the hyperstable maternal microtubule cytoskeleton and apical complex late in parasite division (Figure 4). Upon ERK7 degradation, CSAR1 mislocalizes to the late daughter bud apical cap and conoid (Figures 2, 8) shortly before their disappearance (Figure 6, Supplemental Movie 1). Consistent with a function as an E3 ligase targeting the parasite cytoskeleton, $\Delta c s a r 1$ parasites in the ERK7 ${ }^{\mathrm{AID}}$ background completely rescue the loss of conoid phenotype upon ERK7 degradation.

290 Importantly, we identified CSAR1 an ERK7 interactor by yeast-two-hybrid (Table 2), indicating that these proteins directly interact. Taken together, these data lead us to a model where ERK7 localizes to 
the apical caps of developing daughter parasites both to promote trafficking and assembly of components of the apical complex and IMC cytoskeleton and to protect the daughter buds from premature degradation by CSAR1-mediated ubiquitination (Figure 8).

It has long been appreciated that turnover of maternal secretory organelles (4) and cytoskeleton $(7,17,55)$ was a visible step in parasite division. Furthermore, this process has been suggested to occur at the residual body since the organelle's identification by electron microscopy over 60 years ago $(10,11)$. However, to date, very few proteins that natively and functionally localize to residual body have been identified. We have demonstrated that CSAR1 is involved in protein turnover and normally

300 concentrates at the residual body. This finding provides an important functional validation of the longheld hypothesis that the residual body is a site of organellar recycling. We found that CSAR1 levels begin to build up in the residual body and maternal cytosol late in daughter budding and become restricted to the residual body after cytokinesis. In addition to a retention of maternal cytoskeleton in the residual bodies of $\Delta c s a r 1$ vacuoles (Figure 4), we observed disruption of parasite organization 305 within the vacuole and dysregulation of synchronicity of cell cycle and of daughter-cell counting during replication (Figure 5). Similar phenotypes have been observed both with disruption of components of parasite IMC cytoskeleton $(56,57)$ and of the actin organization of the residual body $(13,14,58)$. Notably, one of these proteins, TgCAP (58), is apically localized and was identified in our ERK7 interactome by BiolD (Table 1). Whether the collection of $\Delta c s a r 1$ phenotypes is a result of a physical

310 block of the residual body by retained maternal cytoskeleton, dysregulation of e.g. monomeric tubulin levels, or disruption of an unidentified CSAR1 client remains to be determined.

An important facet of endodyogeny is that the maternal parasite is infectious until very late in the cell cycle; Toxoplasma may have evolved to divide by this process to maximize its infectivity. However, once the maternal secretory organelles begin to break down, which occurs late in budding (4), the 315 parasite would lose its ability to invade. Thus the maternal cytosol may, at this point, already be considered to be functionally residual body and CSAR1 is an early marker of this transition. The normal versus aberrant functions of CSAR1 suggests Toxoplasma uses residual body localization to 
bioRxiv preprint doi: https://doi.org/10.1101/2021.12.09.471932; this version posted December 9,2021. The copyright holder for this preprint (which was not certified by peer review) is the author/funder, who has granted bioRxiv a license to display the preprint in perpetuity. It is made available under aCC-BY-NC 4.0 International license.

compartmentalize processes with potentially catastrophic consequences to cell health, and ERK7 is one regulator of this spatial restriction (Figure 8). Such a model argues the residual body should be considered a distinct and important organelle with a much more active role in the Toxoplasma lytic cycle than previously appreciated. 


\section{Materials and Methods}

PCR and plasmid generation - All PCR for plasmid generation was conducted using Phusion polymerase (NEB) using primers listed in Supplemental Table 1. Constructs were assembled using

325 Gibson master mix (NEB).

Parasite culture and transfection - Human foreskin fibroblasts (HFF) were grown in Dulbecco's modified Eagle's medium supplemented with $10 \%$ fetal bovine serum and $2 \mathrm{mM}$ glutamine. Toxoplasma tachyzoites were maintained in confluent monolayers of HFF. ERK7-BiolD2-3xHA was created by transfecting the $\mathrm{RH} \Delta k u 80 \Delta h x g p r t$ strain (59) with $50 \mu \mathrm{L}$ of a PCR product using Q5

330 polymerase (NEB) with 500 bp homology arms flanking a BiolD2-3xHA tag together with $5 \mu \mathrm{g}$ of a Cas9 plasmid that had been modified to express HXGPRT and also a gRNA targeting the C-terminus of ERK7 (35). The parasites were selected for HXGPRT expression for 2 days and immediately single cell cloned without selection. (ERK7p)mVenus-BiolD2-3xHA was created by transfecting RH $\Delta h x g p r t$ with a plasmid containing mVenus in frame with BiolD2-3xHA and driven by the ERK7 promoter (1011

335 bp upstream of the ERK7 start). 3xHA tagged interactome candidates were tagged in the background of the ERK7 $7^{\text {AID }}$ strain (35) by transfecting $15 \mu \mathrm{g}$ of linearized plasmids containing a $\sim 1000 \mathrm{bp}$ of targeting sequence in-frame with a C-terminal 3xHA tag. $\Delta c s a r 1$ parasites were created by transfecting $5 \mu \mathrm{g}$ of a plasmid expressing a Cas 9 and a gRNA targeting the ATG of CSAR1 and $50 \mu \mathrm{L}$ of a Q5 PCR product containing a floxed HXGPRT selection cassette flanked by homology arms 5'

340 and 3 ' of the CSAR1 gene. All transfectants were selected with CDMEM + MPA/Xanthine and single cell cloned by serial dilution. All experiments were conducted with parasites that had been cultured for $<1$ month after cloning.

Proximity biotinylation and mass spectrometry - 10x $15 \mathrm{~cm}$ dishes of HFF were infected with either ERK7-BiolD2-3xHA or with (ERK7p)mVenus-BiolD2-3xHA and allowed to grow in the presence

345 of $150 \mu \mathrm{m}$ biotin until parasites began lysing the monolayer ( $36 \mathrm{~h})$. Parasites were released from host cells by passage through a $25 \mathrm{G}$ needle and washed with PBS twice. Parasites were incubated in 2.5 $\mathrm{mL}$ for $1 \mathrm{~h}$ at $4{ }^{\circ} \mathrm{C}$ with RIPA buffer supplemented with protease inhibitors (Sigma). To remove 
exogenous biotin, each sample was buffer exchanged a PD-10 desalting column (GE Healthcare) that had been equilibrated with RIPA buffer. Biotinylated proteins were separated on magnetic streptavidin 350 resin (NEB) and eluted with $2 \times$ SDS loading buffer supplemented with 4\% SDS and $10 \mathrm{mM}$ Bmercaptoethanol. Proteins were separated briefly on a pre-cast 4-20\% SDS PAGE (BioRad) for 6.5 $\min$ at $200 \mathrm{~V}$. The region of the gel containing the samples $(\sim 1 \times 0.5 \mathrm{~cm})$ was excised for downstream processing for mass spectrometry.

Samples were digested overnight with trypsin (Pierce) following reduction and alkylation with DTT 355 and iodoacetamide (Sigma-Aldrich). The samples then underwent solid-phase extraction cleanup with an Oasis HLB plate (Waters) and the resulting samples were injected onto an Orbitrap Fusion Lumos mass spectrometer coupled to an Ultimate 3000 RSLC-Nano liquid chromatography system. Samples were injected onto a $75 \mu \mathrm{m}$ i.d., $75-\mathrm{cm}$ long EasySpray column (Thermo) and eluted with a gradient from $0-28 \%$ buffer B over 90 min. Buffer A contained 2\% (v/v) ACN and $0.1 \%$ formic acid in water, and

360 buffer B contained $80 \%(\mathrm{v} / \mathrm{v}) \mathrm{ACN}, 10 \%(\mathrm{v} / \mathrm{v})$ trifluoroethanol, and $0.1 \%$ formic acid in water. The mass spectrometer operated in positive ion mode with a source voltage of $1.8-2.4 \mathrm{kV}$ and an ion transfer tube temperature of $275^{\circ} \mathrm{C}$. MS scans were acquired at 120,000 resolution in the Orbitrap and up to $10 \mathrm{MS} / \mathrm{MS}$ spectra were obtained in the ion trap for each full spectrum acquired using higher-energy collisional dissociation (HCD) for ions with charges 2-7. Dynamic exclusion was set for $25 \mathrm{~s}$ after an

365 ion was selected for fragmentation.

Raw MS data files were analyzed using Proteome Discoverer v2.4 (Thermo), with peptide identification performed using Sequest HT searching against the Toxoplasma gondii and human protein databases from UniProt. Fragment and precursor tolerances of $10 \mathrm{ppm}$ and $0.6 \mathrm{Da}$ were specified, and three missed cleavages were allowed. Carbamidomethylation of Cys was set as a fixed 370 modification, with oxidation of Met set as a variable modification. The false-discovery rate (FDR) cutoff was $1 \%$ for all peptides. Data have been deposited in the MassIVE database (MSV000088501).

Yeast-2-hybrid screening - Yeast two-hybrid screening was performed by Hybrigenics Services, S.A.S., Evry, France. The coding sequence for Toxoplasma gondii ERK7 was PCR-amplified and 
cloned into pB27 as a C-terminal fusion to LexA (LexA-ERK7). The construct was used as a bait to

screen a random-primed Toxoplasma gondii wt RH strain library constructed into pP6. pB27 and pP6 derive from the original pBTM116 (Vojtek and Hollenberg, 1995) and pGADGH (Bartel et al., 1993) plasmids, respectively. 75 million clones (8-fold the complexity of the library) were screened using a mating approach with YHGX13 (Y187 ade2-101::loxP-kanMX-loxP, mata) and L40 $\Delta$ Gal4 (mata) yeast strains as previously described (Fromont-Racine et al., 1997). 267 His + colonies were selected on a medium lacking tryptophan, leucine and histidine, and supplemented with $5 \mathrm{mM}$ 3-aminotriazole to handle bait autoactivation. The prey fragments of the positive clones were amplified by PCR and sequenced to identify the corresponding interacting proteins.

Plaque assays - To measure plaque efficiency, 200 of each ERK $7^{\mathrm{AID}}$ and $\Delta c s a r 1$ parasites were allowed to infect confluent HFF in one well of a 6 well plate in the either the presence or absence of IAA. After 7 days, the monolayer was fixed with $\mathrm{MeOH}$, stained with crystal violet, and the resulting plaques counted. All plaque assays were performed in technical and biological triplicate. Plaque areas were quantified in ImageJ (60).

Immunofluorescence - HFF cells were grown on coverslips in 24-well plates until confluent and were infected with parasites. The cells were rinsed twice with phosphate buffered saline (PBS), and were fixed with $4 \%$ paraformaldehyde/4\% sucrose in PBS at room temperature for 15 min. After two washes with PBS, cells were permeabilized with $0.1 \%$ Triton-X-100 in PBS for 10 min and washed $3 x$ with PBS. After blocking in PBS $+3 \%$ BSA for 30 min, cells were incubated in primary antibody in blocking solution overnight at room temperature. Cells were then washed $3 x$ with PBS and incubated with Alexa-fluor conjugated secondary antibodies (Molecular Probes) for $2 \mathrm{~h}$ and Hoescht, where

395 appropriate. Cells were then washed $3 x$ with PBS and then mounted with mounting medium (Vector Laboratories). Cells were imaged on either a Nikon A1 Laser Scanning Confocal Microscope or a Nikon Ti2E wide-field microscope. Primary antibodies used in this study include rat anti-HA (Sigma; 1:1000 dilution), mouse m2 anti-FLAG (1:1,000 dilution; Sigma), rabbit anti-Tg- $\beta$-tubulin $(1: 10,000$ dilution), guinea pig anti-TgERK7 (1:10,000 dilution), mouse anti-IMC1 (1:1000 dilution; gift of Gary 
400 Ward), anti-GRA1 (1:1000 dilution; BioVision), mouse anti-ROP2 (1:1000 dilution), mouse anti-MIC2 (1:1000 dilution; gift of Vern Carruthers), and mouse anti-ISP1 (1:1000 dilution; gift of Peter Bradley). All micrographs are representative of 20 of 20 images collected.

Live cell imaging - ERK $7^{\mathrm{AID}}$ or $\Delta c s a r 1$ parasites were syringe released from a T25 of a highly infected monolayer and passed through a $5 \mu \mathrm{m}$ syringe filter (Pall) to remove cell debris. $\sim 1 \times 10^{6}$

405 parasites were added to a confluent monolayer of HFFs grown on a Lab-Tek 8-well \#1.5 glassbottomed chamber slide (Thermo) and allowed to invade and grow for $4-5 \mathrm{~h}$ at $37{ }^{\circ} \mathrm{C}$ in a $5 \% \mathrm{CO}_{2}$ incubator, after which time the well was washed extensively with warm HBSS ( $>5 \times)$ to remove extracellular parasites and the media was changed to either CDMEM $\pm 500 \mu \mathrm{M}$ IAA. The chamber slide was transferred to a Tokai Hit environment chamber mounted on a Ti2 Nikon wide-field microscope 410 and maintained at $37{ }^{\circ} \mathrm{C}$ and $5 \% \quad \mathrm{CO}_{2}$. Parasite division was visualized by eGFP- $\alpha$-tubulin fluorescence using a 100× NA 1.45 Pan Apo oil immersion objective (Nikon). Briefly, 10-15 regions were selected containing parasites with visible early buds. Images were collected every 2 min for 2-3 h as $10 \mu \mathrm{m}$ stacks of $1 \mu \mathrm{m}$ slices that were then maximum-intensity Z-projected. Movies were rendered using a custom Python script interfacing with Inkscape v1.1.1 and ffmpeg.

415 Western blotting - Proteins were separated by SDS-PAGE and transferred to a PVDF membrane. Membranes were blocked for $1 \mathrm{~h}$ in PBS $+5 \%$ milk, followed by overnight incubation at $4^{\circ} \mathrm{C}$ with primary antibody in blocking solution. The next day, membranes were washed $3 \times$ with TBST, followed by incubation at room temperature for 1-2 $\mathrm{h}$ with HRP-conjugated secondary antibody (Sigma) in blocking buffer. After $3 \times$ washes with TBST, western blots were imaged using ECL Plus reagent 420 (Pierce) on a GE ImageQuant LAS4000. Antibodies used in this study include: Rb anti-Tg- $\beta$-tubulin (1:5,000 dilution) and mouse m2 anti-FLAG (Sigma; 1:1,000 dilution).

Invasion and egress assays - For invasion assays, highly infected monolayers were mechanically disrupted by passage through a 27 gauge needle to release them. $1 \times 10^{6}$ parasites of each strain tested (all expressing eGFP-a-tubulin) were added to HFF monolayer grown in a 24 well with coverslip 425 and incubated for $2 \mathrm{~h}$ at $37^{\circ} \mathrm{C}$. These were then washed $10 \times$ with PBS and fixed and prepared for 
imaging. $3.15 \mathrm{~mm}^{2}$ area $(\sim 1 \%$ of total well) were imaged per experiment and images analyzed in ImageJ. Invasion rates of all strains were normalized to the average of the ERK7 ${ }^{\text {AID }}$-IAA condition. For egress assays, parasites were allowed to grow for 24-36 h in HFF grown in a 24 well with coverslip. Parasites were incubated in pre-warmed HBSS containing $1 \mu \mathrm{M}$ calcium ionophore A23187 (Cayman

430 Chemical) for $1 \mathrm{~min}$ at $37^{\circ} \mathrm{C}$ before fixation in PFA, staining with anti-GRA1 antibody as a marker for intact vacuoles, and subsequent imaging. Egress rates were quantified by normalizing the number of intact vacuoles to a matching experimental set that was fixed without ionophore treatment.

Transmission electron microscopy - Parasite ghosts were prepared essentially as described in (61). T25 flasks of parasites were grown in either $500 \mu$ IAA or vehicle media for $48 \mathrm{~h}$. The highly

435 infected T25s were syringe released, passed through a $5 \mu \mathrm{m}$ filter, washed with Hanks Buffered Saline solution, and then brought up in $50 \mathrm{ul}$ of $20 \mu \mathrm{M}$ calcium ionophore in HBSS. The parasites were then incubated at $37^{\circ} \mathrm{C}$ for $10 \mathrm{~min} .4 \mu \mathrm{l}$ of the parasite suspension were allowed to adhere to a grid, after which membranes were extracted by addition of $0.5 \%$ Triton-X-100 in PBS for $3-4$ min. The grids were then briefly washed with MilliQ and then stained with $0.5 \%$ phosphotungstic acid, $\mathrm{pH} 7.4$ for $30 \mathrm{~s}$. The

440 phosphotungstic acid was wicked off and the grids were again washed with MilliQ and allowed to dry. All TEM images were acquired on a Tecnai G2 spirit transmission electron microscope (FEI) equipped with a $\mathrm{LaB}_{6}$ source at $120 \mathrm{kV}$.

Figure generation - Data plotting and statistical analyses were conducted using the Python SciPy, Matplotlib, and Seaborn packages. All figures were created in Inkscape v0.92.

\section{Acknowledgments}

We thank Melanie Cobb for nomenclature suggestions; Josh Beck and Ben Weaver for helpful comments on the manuscript; the UT Southwestern Electron Microscopy and UT Southwestern Proteomics core facilities for assistance with data collection and analysis. M.L.R. acknowledges funding from the Welch Foundation (I-2075-20210327), National Science Foundation (MCB1553334),

450 and NIH (Al150715). X.H. was funded, in part, by Cancer Prevention and Research Institute of Texas Training Grant RP160157. S.A.H. was funded, in part, by an NSF GRFP. 
bioRxiv preprint doi: https://doi.org/10.1101/2021.12.09.471932; this version posted December 9, 2021. The copyright holder for this preprint (which was not certified by peer review) is the author/funder, who has granted bioRxiv a license to display the preprint in perpetuity. It is made available under aCC-BY-NC 4.0 International license.

\section{Conflict of Interests}

The authors declare that they have no conflict of interest. 


\section{References}

1. M.-J. Gubbels, et al., Fussing About Fission: Defining Variety Among Mainstream and Exotic Apicomplexan Cell Division Modes. Front. Cell. Infect. Microbiol. 10, 269 (2020).

2. M.-J. Gubbels, I. Coppens, K. Zarringhalam, M. T. Duraisingh, K. Engelberg, The Modular Circuitry of Apicomplexan Cell Division Plasticity. Front. Cell. Infect. Microbiol. 11, 670049 (2021).

3. M. E. Francia, B. Striepen, Cell division in apicomplexan parasites. Nat. Rev. Microbiol. 12, 125-136 (2014).

4. M. Nishi, K. Hu, J. M. Murray, D. S. Roos, Organellar dynamics during the cell cycle of Toxoplasma gondii. J. Cell Sci. 121, 1559-1568 (2008).

5. L. Pelletier, et al., Golgi biogenesis in Toxoplasma gondii. Nature 418, 548-552 (2002).

6. D. T. Riglar, et al., Spatial association with PTEX complexes defines regions for effector export into Plasmodium falciparum-infected erythrocytes. Nat. Commun. 4, 1415 (2013).

7. J. Q. Tran, et al., RNG1 is a late marker of the apical polar ring in Toxoplasma gondii. Cytoskelet. Hoboken NJ 67, 586-598 (2010).

8. B. R. Anderson-White, et al., A family of intermediate filament-like proteins is sequentially assembled into the cytoskeleton of Toxoplasma gondii. Cell. Microbiol. 13, 18-31 (2011).

9. B. Anderson-White, et al., Cytoskeleton assembly in Toxoplasma gondii cell division. Int. Rev. Cell Mol. Biol. 298, 1-31 (2012).

10. M. Goldman, R. K. Carver, A. J. Sulzer, Reproduction of Toxoplasma gondii by internal budding. J. Parasitol. 44, 161-171 (1958).

11. M. A. Gavin, T. Wanko, L. Jacobs, Electron microscope studies of reproducing and interkinetic Toxoplasma. J. Protozool. 9, 222-234 (1962).

12. M. Attias, K. Miranda, W. De Souza, Development and fate of the residual body of Toxoplasma gondii. Exp. Parasitol. 196, 1-11 (2019).

13. J. Periz, et al., Toxoplasma gondii F-actin forms an extensive filamentous network required for material exchange and parasite maturation. eLife 6 (2017).

14. N. Tosetti, N. Dos Santos Pacheco, D. Soldati-Favre, D. Jacot, Three F-actin assembly centers regulate organelle inheritance, cell-cell communication and motility in Toxoplasma gondii. eLife 8 (2019).

15. E. S. Suvorova, M. Francia, B. Striepen, M. W. White, A novel bipartite centrosome coordinates the apicomplexan cell cycle. PLoS Biol. 13, e1002093 (2015).

16. C.-T. Chen, M.-J. Gubbels, TgCep250 is dynamically processed through the division cycle and is essential for structural integrity of the Toxoplasma centrosome. Mol. Biol. Cell 30, 1160-1169 (2019). 
17. K. Hu, et al., Daughter cell assembly in the protozoan parasite Toxoplasma gondii. Mol. Biol. Cell 13, 593-606 (2002).

18. B. Striepen, et al., The plastid of Toxoplasma gondii is divided by association with the centrosomes. J. Cell Biol. 151, 1423-1434 (2000).

19. C. A. Alvarez, E. S. Suvorova, Checkpoints of apicomplexan cell division identified in Toxoplasma gondii. PLoS Pathog. 13, e1006483 (2017).

20. X. Hu, W. J. O'Shaughnessy, T. G. Beraki, M. L. Reese, Loss of the Conserved Alveolate Kinase MAPK2 Decouples Toxoplasma Cell Growth from Cell Division. mBio 11 (2020).

21. C.-T. Chen, M.-J. Gubbels, The Toxoplasma gondii centrosome is the platform for internal daughter budding as revealed by a Nek1 kinase mutant. J. Cell Sci. 126, 3344-3355 (2013).

22. L. Koreny, et al., Molecular characterization of the conoid complex in Toxoplasma reveals its conservation in all apicomplexans, including Plasmodium species. PLoS Biol. 19, e3001081 (2021).

23. E. Bertiaux, et al., Expansion microscopy provides new insights into the cytoskeleton of malaria parasites including the conservation of a conoid. PLoS Biol. 19, e3001020 (2021).

24. Z. Füssy, P. Masařová, J. Kručinská, H. J. Esson, M. Oborník, Budding of the Alveolate Alga Vitrella brassicaformis Resembles Sexual and Asexual Processes in Apicomplexan Parasites. Protist 168, 80-91 (2017).

25. N. Okamoto, P. J. Keeling, The 3D structure of the apical complex and association with the flagellar apparatus revealed by serial TEM tomography in Psammosa pacifica, a distant relative of the Apicomplexa. PloS One 9, e84653 (2014).

26. K. Hu, D. S. Roos, J. M. Murray, A novel polymer of tubulin forms the conoid of Toxoplasma gondii. J. Cell Biol. 156, 1039-1050 (2002).

27. J. C. de Leon, et al., A SAS-6-like protein suggests that the Toxoplasma conoid complex evolved from flagellar components. Eukaryot. Cell 12, 1009-1019 (2013).

28. M. E. Francia, et al., Cell division in Apicomplexan parasites is organized by a homolog of the striated rootlet fiber of algal flagella. PLoS Biol. 10, e1001444 (2012).

29. M. E. Francia, J.-F. Dubremetz, N. S. Morrissette, Basal body structure and composition in the apicomplexans Toxoplasma and Plasmodium. Cilia 5, 3 (2015).

30. G. Lentini, D. J. Dubois, B. Maco, D. Soldati-Favre, K. Frénal, The roles of Centrin 2 and Dynein Light Chain 8a in apical secretory organelles discharge of Toxoplasma gondii. Traffic Cph. Den. 20, 583-600 (2019).

31. M. F. Lévêque, L. Berry, S. Besteiro, An evolutionarily conserved SSNA1/DIP13 homologue is a component of both basal and apical complexes of Toxoplasma gondii. Sci. Rep. 6, 27809 (2016).

32. M. G. Del Carmen, M. Mondragón, S. González, R. Mondragón, Induction and regulation of conoid extrusion in Toxoplasma gondii. Cell. Microbiol. 11, 967-982 (2009). 
33. V. B. Carruthers, L. D. Sibley, Mobilization of intracellular calcium stimulates microneme discharge in Toxoplasma gondii. Mol. Microbiol. 31, 421-428 (1999).

34. A. Graindorge, et al., The Conoid Associated Motor MyoH Is Indispensable for Toxoplasma gondii Entry and Exit from Host Cells. PLoS Pathog. 12, e1005388 (2016).

35. W. J. O'Shaughnessy, X. Hu, T. Beraki, M. McDougal, M. L. Reese, Loss of a conserved MAPK causes catastrophic failure in assembly of a specialized cilium-like structure in Toxoplasma gondii. Mol. Biol. Cell 31, 881-888 (2020).

36. K. Nishimura, T. Fukagawa, H. Takisawa, T. Kakimoto, M. Kanemaki, An auxin-based degron system for the rapid depletion of proteins in nonplant cells. Nat. Methods 6, 917-22 (2009).

37. P. S. Back, et al., Ancient MAPK ERK7 is regulated by an unusual inhibitory scaffold required for Toxoplasma apical complex biogenesis. Proc. Natl. Acad. Sci. U. S. A. 117, 12164-12173 (2020).

38. N. Tosetti, et al., Essential function of the alveolin network in the subpellicular microtubules and conoid assembly in Toxoplasma gondii. eLife 9 (2020).

39. D. Sang, et al., Ancestral reconstruction reveals mechanisms of ERK regulatory evolution. eLife 8 (2019).

40. K. J. Roux, D. I. Kim, B. Burke, BiolD: a screen for protein-protein interactions. Curr. Protoc. Protein Sci. 74, Unit 19.23. (2013).

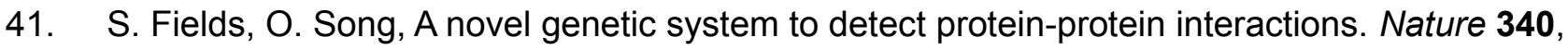
245-246 (1989).

42. K. J. Roux, D. I. Kim, M. Raida, B. Burke, A promiscuous biotin ligase fusion protein identifies proximal and interacting proteins in mammalian cells. J. Cell Biol. 196, 801-10 (2012).

43. D. I. Kim, et al., Probing nuclear pore complex architecture with proximity-dependent biotinylation. Proc. Natl. Acad. Sci. U. S. A. 111, E2453-2461 (2014).

44. D. I. Kim, et al., An improved smaller biotin ligase for BiolD proximity labeling. Mol. Biol. Cell 27, 1188-1196 (2016).

45. K. Hu, et al., Cytoskeletal components of an invasion machine--the apical complex of Toxoplasma gondii. PLoS Pathog. 2, e13 (2006).

46. K. Hu, D. S. Roos, S. O. Angel, J. M. Murray, Variability and heritability of cell division pathways in Toxoplasma gondii. J. Cell Sci. 117, 5697-5705 (2004).

47. K. Miyatake, M. Kusakabe, C. Takahashi, E. Nishida, ERK7 regulates ciliogenesis by phosphorylating the actin regulator CapZIP in cooperation with Dishevelled. Nat. Commun. 6 , 6666 (2015).

48. A. Kazatskaya, et al., Primary Cilium Formation and Ciliary Protein Trafficking Is Regulated by the Atypical MAP Kinase MAPK15 in Caenorhabditis elegans and Human Cells. Genetics 207, 1423-1440 (2017). 
49. Y. Wei, Z. Li, Distinct roles of a mitogen-activated protein kinase in cytokinesis between different life cycle forms of Trypanosoma brucei. Eukaryot. Cell 13, 110-118 (2014).

50. M. Zacharogianni, et al., ERK7 is a negative regulator of protein secretion in response to aminoacid starvation by modulating Sec16 membrane association. EMBO J. 30, 3684-3700 (2011).

51. J. A. Brzostowski, et al., Phosphorylation of chemoattractant receptors regulates chemotaxis, actin reorganization and signal relay. J. Cell Sci. 126, 4614-4626 (2013).

52. J. Chia, K. M. Tham, D. J. Gill, E. A. Bard-Chapeau, F. A. Bard, ERK8 is a negative regulator of O-GalNAc glycosylation and cell migration. eLife 3, e01828 (2014).

53. D. P. Bermingham, et al., The Atypical MAP Kinase SWIP-13/ERK8 Regulates Dopamine Transporters through a Rho-Dependent Mechanism. J. Neurosci. Off. J. Soc. Neurosci. 37, 9288-9304 (2017).

54. D. Colecchia, et al., MAPK15/ERK8 stimulates autophagy by interacting with LC3 and GABARAP proteins. Autophagy 8, 1724-1740 (2012).

55. D. T. Ouologuem, D. S. Roos, Dynamics of the Toxoplasma gondii inner membrane complex. J. Cell Sci. 127, 3320-3330 (2014).

56. R. Dubey, et al., Differential Roles for Inner Membrane Complex Proteins across Toxoplasma gondii and Sarcocystis neurona Development. mSphere 2, e00409-17 (2017).

57. J. R. Beck, et al., A novel family of Toxoplasma IMC proteins displays a hierarchical organization and functions in coordinating parasite division. PLoS Pathog. 6, e1001094 (2010).

58. A. Hunt, et al., Differential requirements for cyclase-associated protein (CAP) in actindependent processes of Toxoplasma gondii. eLife 8 (2019).

59. M. Huynh, V. B. Carruthers, Tagging of endogenous genes in a Toxoplasma gondii strain lacking Ku80. Eukaryot. Cell 8, 530-9 (2009).

60. J. Schindelin, et al., Fiji: an open-source platform for biological-image analysis. Nat. Methods 9, 676-682 (2012).

61. E. Nagayasu, Y.-C. Hwang, J. Liu, J. M. Murray, K. Hu, Loss of a doublecortin (DCX)-domain protein causes structural defects in a tubulin-based organelle of Toxoplasma gondii and impairs host-cell invasion. Mol. Biol. Cell 28, 411-428 (2017).

62. S. Long, B. Anthony, L. L. Drewry, L. D. Sibley, A conserved ankyrin repeat-containing protein regulates conoid stability, motility and cell invasion in Toxoplasma gondii. Nat. Commun. 8, 2236 (2017). 
Figure 1

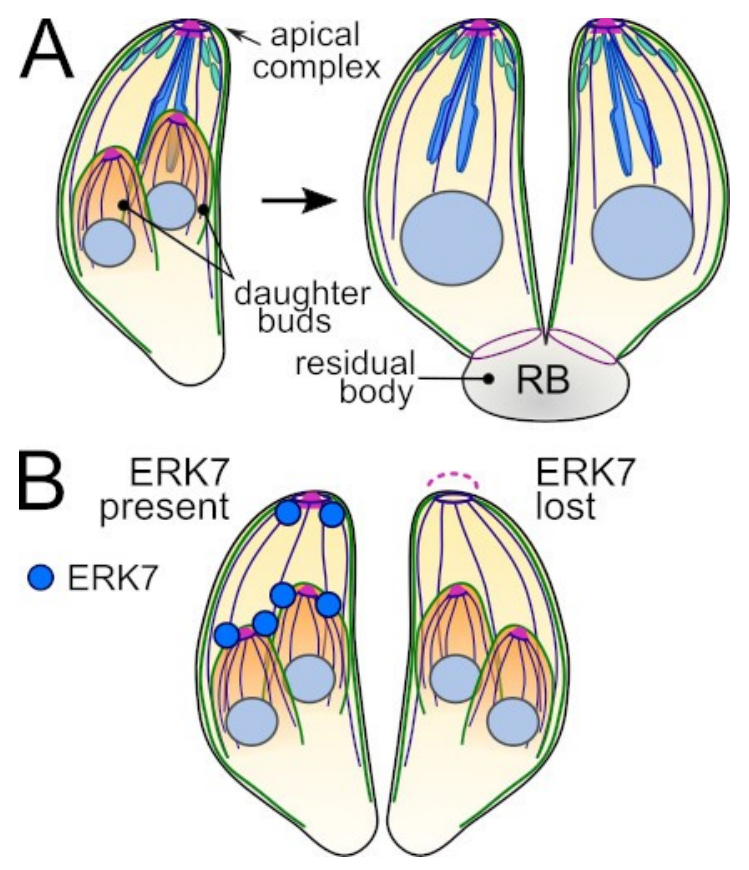

Figure 1: Toxoplasma divides by endodyogeny. (A) In normal Toxoplasma division, two daughter parasites are formed within the intact mother cell and are delineated a specialized cytoskeleton and membrane structure called the inner membrane complex (IMC; green). During cytokinesis, the daughter cells integrate their cytoskeleton into the mother plasma membrane. After division, the parasites remain connected through the "residual body." (B) Diagram of ERK7 kinase loss-of-function phenotype in Toxoplasma division. When parasites divide without functional ERK7 kinase localized at their apical tips, the conoid (magenta) is lost in the mature parasite after cytokinesis, rendering the parasites noninvasive. Note that new daughter parasites grow and develop with a visible conoid. 
Table 1

\begin{tabular}{|c|c|c|c|}
\hline \multicolumn{4}{|c|}{ Apical cap } \\
\hline $\mathrm{Y} 2 \mathrm{H}$ & BiolD & Gene ID & Gene Name \\
\hline$\checkmark$ & $\checkmark$ & $\mathrm{TG}^{*}{ }_{2} 246950$ & AC9 \\
\hline$\checkmark$ & $\checkmark$ & TG $^{*} 2_{292950}$ & AC10 \\
\hline & $\checkmark$ & TG*_250820 & AC2 \\
\hline & $\checkmark$ & $\mathrm{TG}^{*}{ }_{-} 214880$ & AC4 \\
\hline & $\checkmark$ & $\mathrm{TG}^{*}{ }_{2} 229640$ & AC8 \\
\hline & $\checkmark$ & $\mathrm{TG}^{*} \_310030$ & TgCAP \\
\hline \multicolumn{4}{|c|}{ Inner membrane complex } \\
\hline & $\checkmark$ & $\mathrm{TG}^{*}{ }_{-} 310930$ & TgFBXO1 \\
\hline & $\checkmark$ & TG*_316540 & ISP3 \\
\hline & $\checkmark$ & $\mathrm{TG}^{*}{ }^{-} 231640$ & IMC1 \\
\hline & $\checkmark$ & TG $^{*} 231630$ & IMC4 \\
\hline & $\checkmark$ & TG $^{*} 230210$ & IMC10 \\
\hline & $\checkmark$ & $\mathrm{TG}^{*} \_235340$ & ISC1 \\
\hline \multicolumn{4}{|c|}{ Conoid } \\
\hline & $\checkmark$ & $\mathrm{TG}^{*}{ }_{2} 252880$ & CRMP \\
\hline & $\checkmark$ & $T^{*} G^{*} 246720 \dagger$ & Hypothetical \\
\hline \multicolumn{4}{|r|}{ Other } \\
\hline$\checkmark$ & $\checkmark$ & $\mathrm{TG}^{*} 239885$ & (Hypothetical) Protein Kinase \\
\hline
\end{tabular}

†Previously identified at conoid by proximity biotinylation (62)

Table 1: Hits in ERK7 interactome with known localization.

Table 2

\begin{tabular}{|c|c|c|c|c|}
\hline $\mathrm{Y} 2 \mathrm{H}$ & BiolD & Gene ID & Gene Name & Localization \\
\hline$\checkmark$ & $\checkmark$ & TG $^{*} \_238380$ & Hypothetical & Apical cap \\
\hline$\checkmark$ & $\checkmark$ & TG*_285140 & Hypothetical & Apical dot \\
\hline$\checkmark$ & & $\mathrm{TG}^{*} 236060$ & Hypothetical & Cytosolic/apical cap \\
\hline$\checkmark$ & & TG $^{*}$ _260500‡ & Hypothetical & IMC sutures \\
\hline & $\checkmark$ & TG $^{*} \_231210 \ddagger$ & Epsin-like & Apical/endosomal? \\
\hline & $\checkmark$ & $\mathrm{TG}^{*} 309560 \ddagger$ & Bax-like & Apical/endosomal? \\
\hline$\checkmark$ & & TG*_315950 & CSAR1 & $\begin{array}{l}\text { Residual body (-IAA)/ } \\
\text { apical cap (+IAA) }\end{array}$ \\
\hline
\end{tabular}

$\ddagger$ Previously identified in published conoid proteome (45)

Table 2: Hits in ERK7 interactome localized in this study. 


\section{Figure 2}
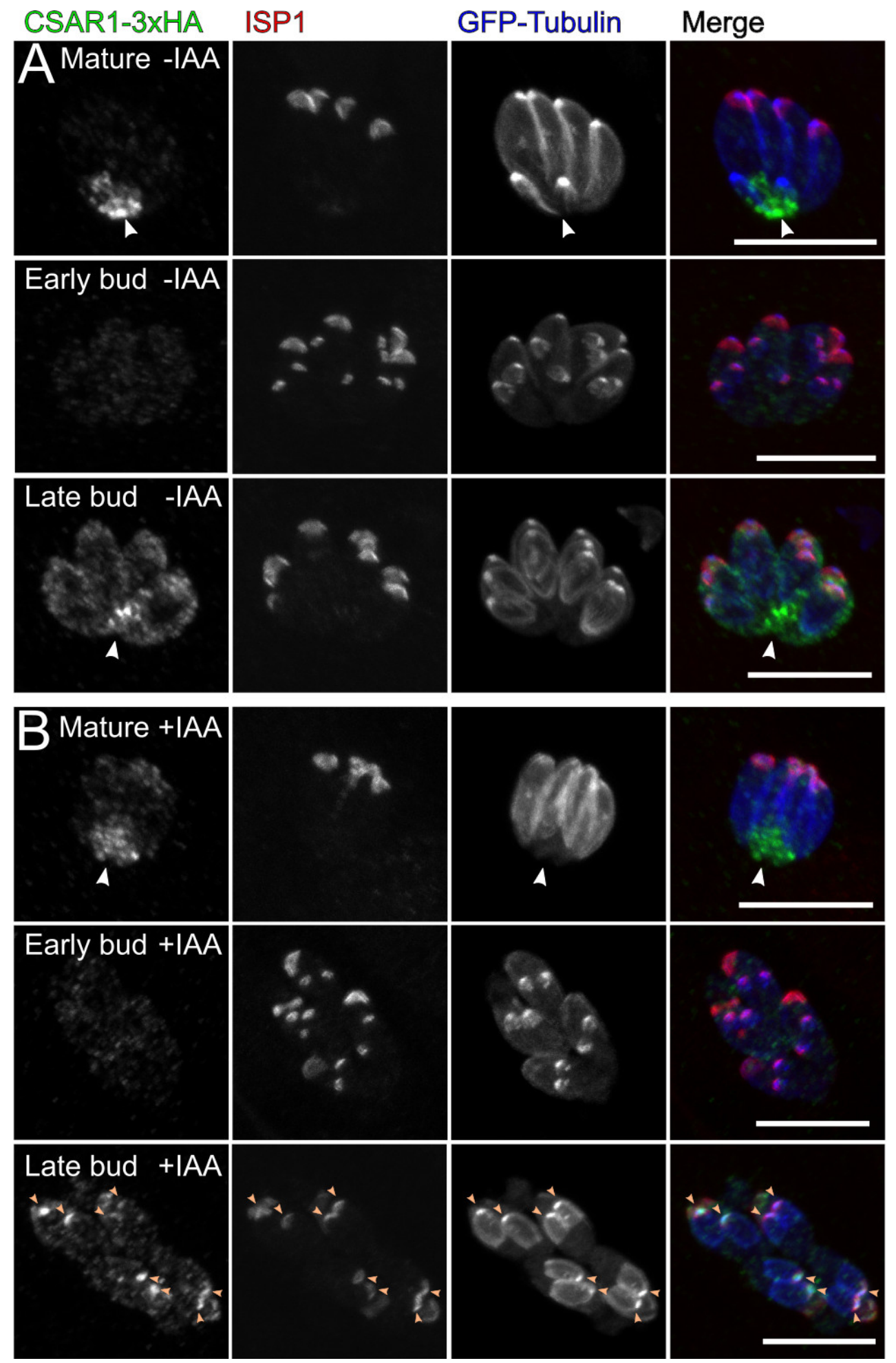

Figure 2: CSAR1 mislocalizes to daughter buds upon ERK7 degradation. Maximum intensity Zprojections of confocal stacks of CSAR1-3xHA ERK7 ${ }^{\text {AID }}$ parasites grown for $24 \mathrm{~h}(\mathrm{~A})$ without IAA and (B) with IAA to degrade ERK7 ${ }^{\text {AID }}$. Parasites were visualized with GFP-tubulin (blue), and antibodies against HA (green) and the apical cap marker ISP1 (red). Concentration of CSAR1 signal at the residual body is indicated with a white arrow. The apical ends of the late daughter buds in the +IAA condition are indicated with orange arrows. Parasites were captured at the indicated points in the cell cycle. All scale bars are 10 $\mu \mathrm{m}$. 
Figure 3
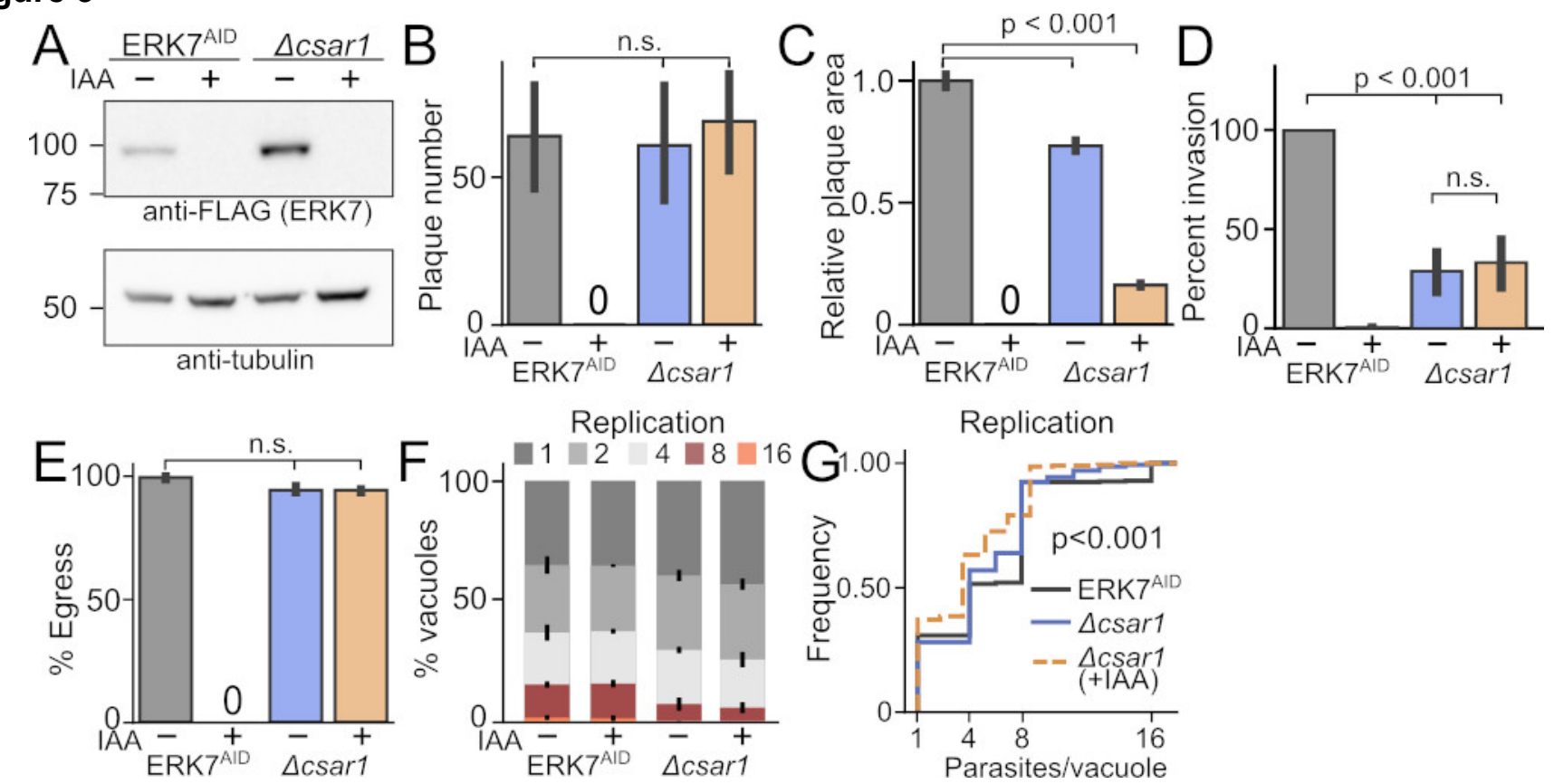

Replication
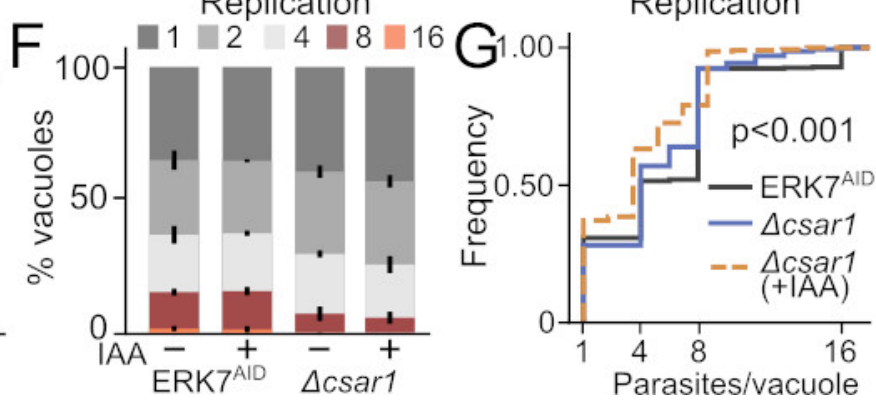

Figure 3: CSAR1 is required for full efficiency of lytic cycle. (A) Western blot stained with anti-FLAG (recognizing ERK $7^{A I D-3 \times F L A G}$ ) and anti-tubulin of lysates from ERK ${ }^{\text {AID }}$ and $\triangle$ csar1 parasites grown in \pm IAA. Quantification of $(B)$ plaque number, $(C)$ relative plaque size, $(D)$ invasion rate, $(E)$ ionophore-induced egress, and $(F)$ replication rates of ERK $7^{\text {AID }}$ or $\Delta c$ csar1 parasites grown in \pm IAA binned as indicated. $(G)$ is the unbinned cumulative frequency of the data from $(F)$. Invasion and egress are $n=3$ replicates. Replication quantified from 3 replicates of $n \geq 100$ vacuoles. Error bars on (F) are s.d., all others are $95 \%$ confidenceinterval of mean. Replication of $\Delta c s a r 1$ compared to parental ERK $7^{\text {AID }}$ is $p<0.001$ as calculated by Kolmogorov-Smirnov test. 
Figure 4

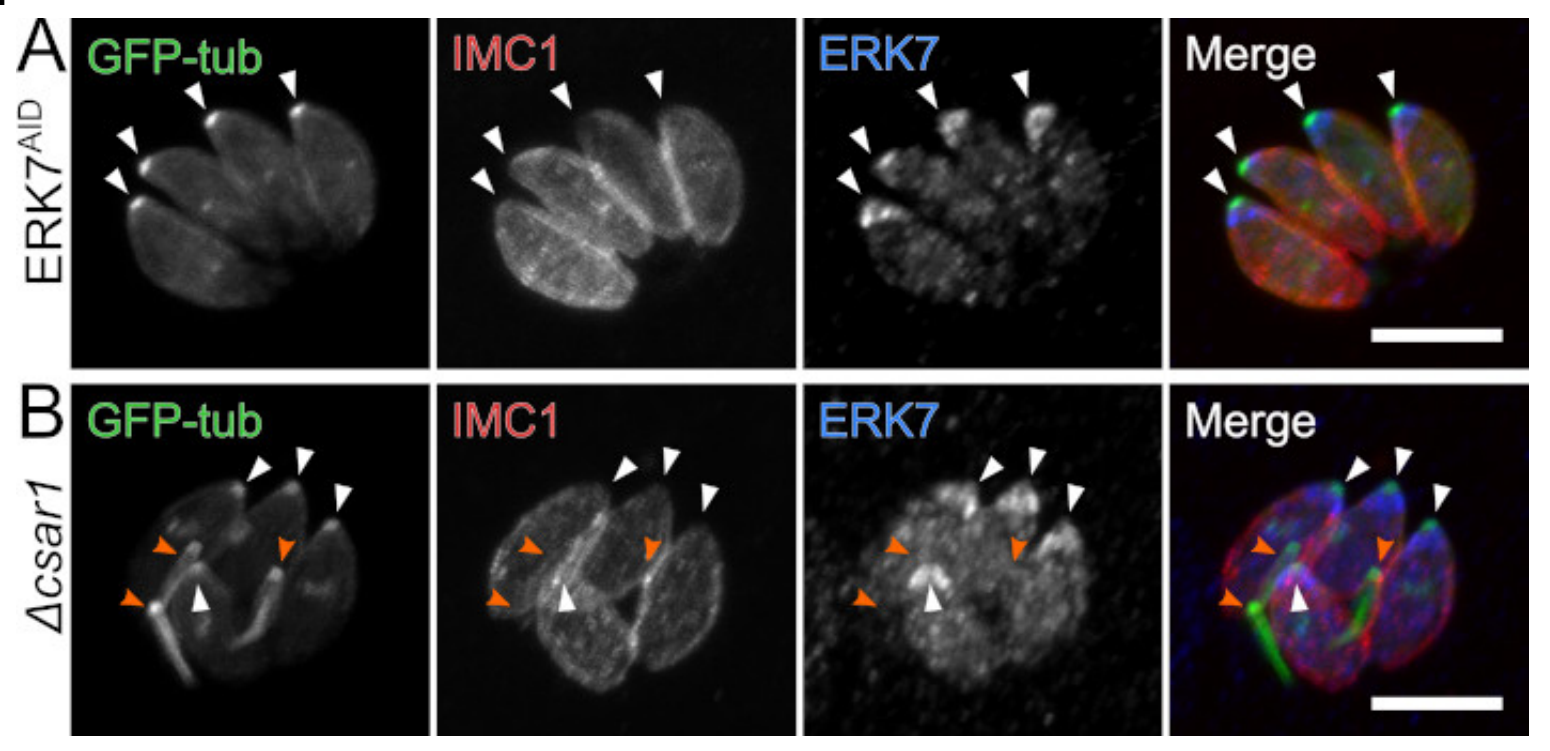

Figure 4: Loss of CSAR1 causes retention of maternal cytoskeleton in the residual body. Maximum intensity Z-projections of confocal stacks of (A) ERK7 $7^{\mathrm{AID}}$ and (B) $\Delta c s a r 1$ parasites grown in the absence of IAA. Parasites were visualized with GFP-tubulin (green), and antibodies against the inner membrane complex marker IMC1 (red) and ERK7 (blue). Apical ends of parasites are indicated with white arrows. Retained cytoskeleton from the previous two divisions in the $\Delta c s a r 1$ vacuole is indicated with orange arrows. Scale bars are $5 \mu \mathrm{m}$. 
Figure 5
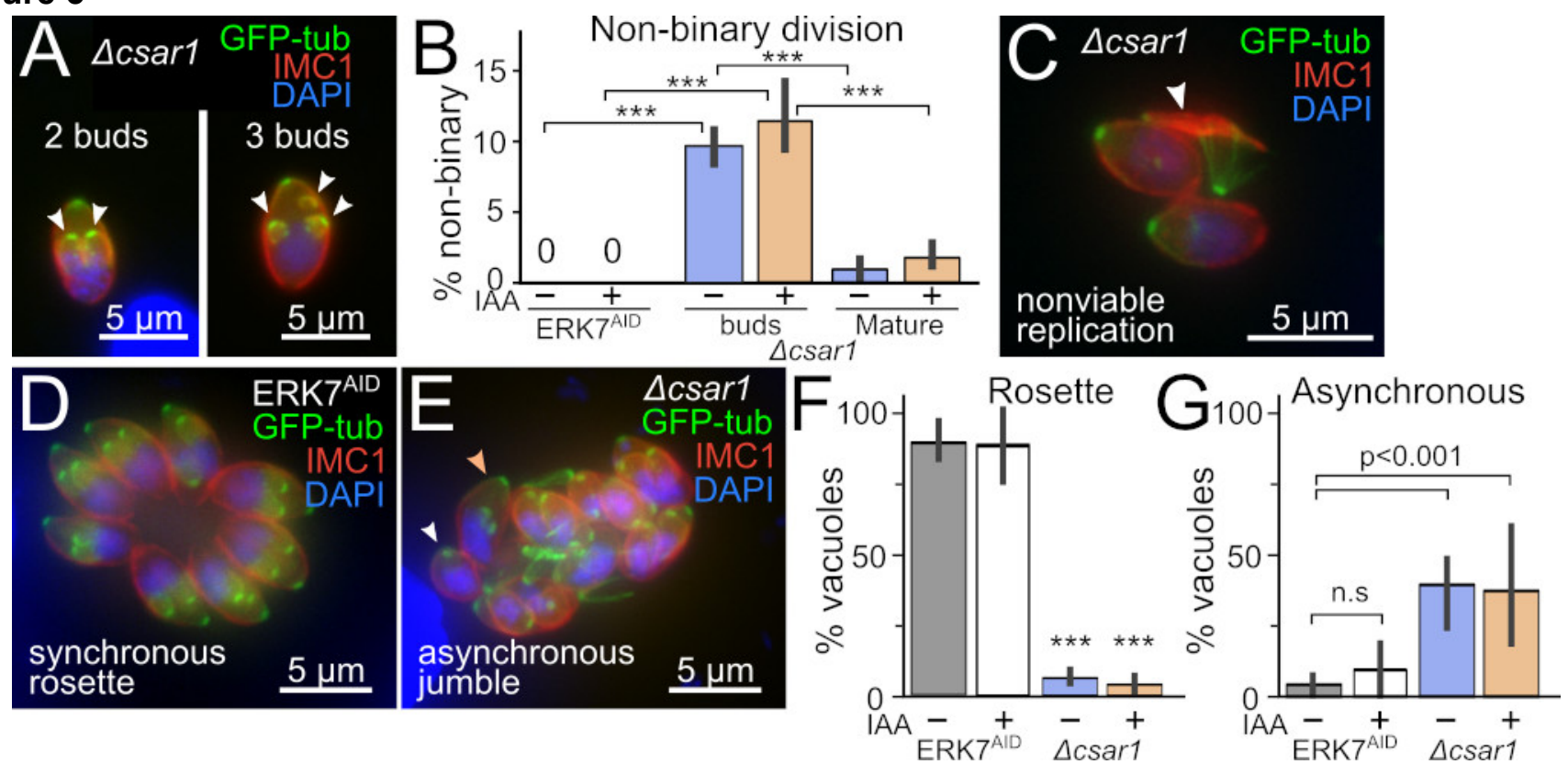

Figure 5: $\Delta$ csar1 parasites exhibit multiple defects in cell cycle. (A) Representative images of $\Delta$ csar1 parasites dividing normally (2 buds) or abnormally (3 buds). (B) Quantification of non-binary division for ERK7 ${ }^{\mathrm{AID}}$ and $\Delta$ csar1 parasites. "buds" and "mature" respectively indicate actively dividing parasites or newly divided, mature parasites. (C) Representative image of a recently divided $\Delta$ csar1 parasite showing the remains of a nonviable parasite (white arrow). Representative images of (D) ERK7 $7^{\text {AID }}$ parasites dividing synchronously within a normal rosette vacuole and (E) $\Delta c s a r 1$ parasites dividing asynchronously (white arrow: nonbudding; orange arrow: early buds; other parasites: late buds) in a "jumbled" vacuole. Quantification of $(F)$ Rosette/Jumbled and $(G)$ Asynchronous division phenotypes. Phenotypes quantified from 3 replicates of $n \geq 100$ vacuoles. Error bars are $95 \%$ confidence interval of mean. $p$-values are 1-way ANOVA followed by Tukey's test. $\left({ }^{* * *}, p<0.001\right)$ 
Figure 6
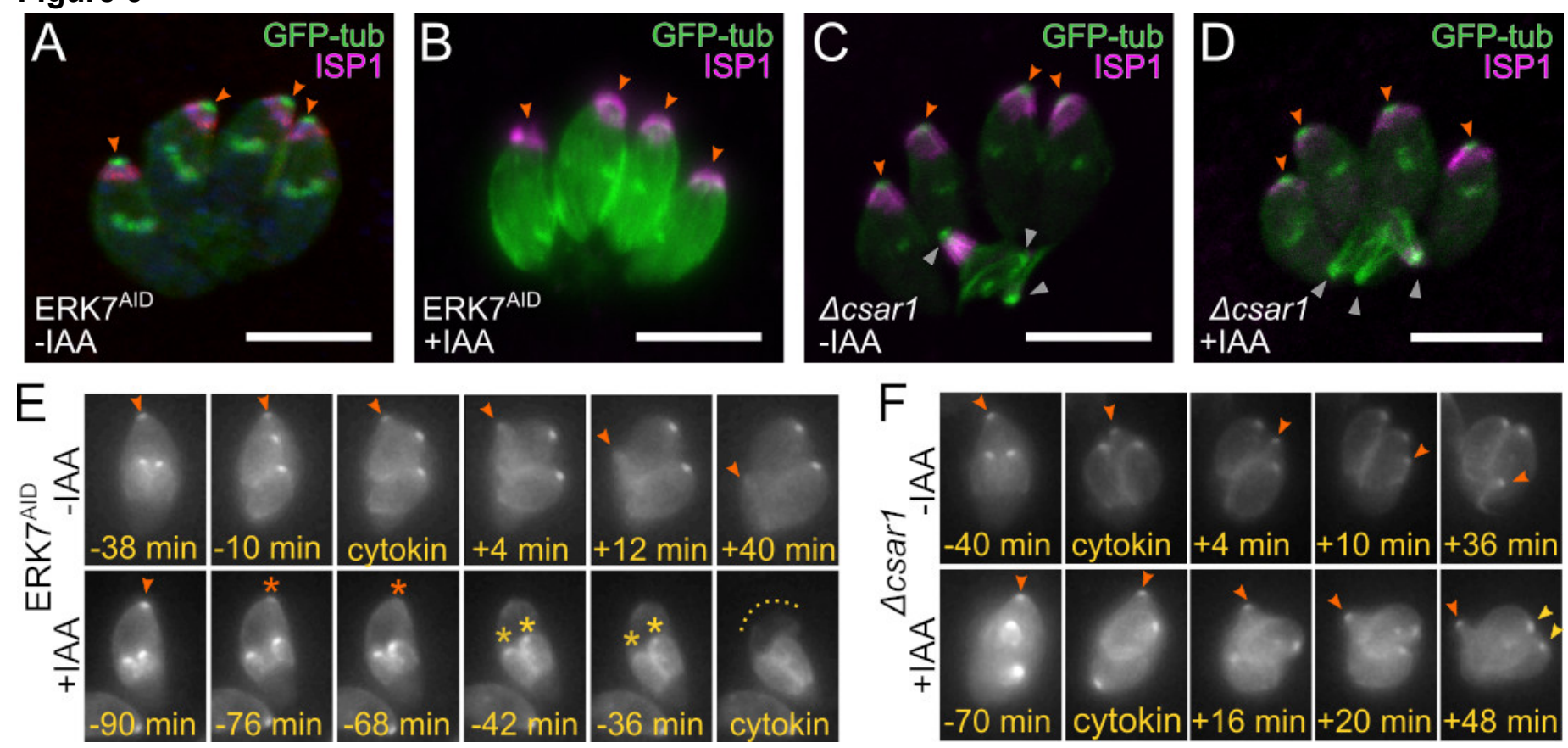

Figure 6: Loss of CSAR1 protects the conoid upon ERK7 degradation. (A-D) Maximum intensity Zprojections of confocal stacks of the indicated parasite strains grown in \pm IAA and visualized with GFPtubulin (green) and an antibody against the apical cap marker ISP1 (magenta). Apical ends of parasites are indicated with orange arrows. Retained cytoskeleton in the $\Delta c s a r 1$ residual body is indicated with gray arrows. All scale bars are $5 \mu \mathrm{m}$. (E) Stills from live cell imaging of GFP-tubulin in dividing ERK7 ${ }^{\text {AID }}$ parasites grown in \pm IAA. The time before (-) and after (+) cytokinesis is indicated. Maternal conoid is indicated with an orange arrow (or orange star when degraded). Daughter conoids are indicated with gold stars at point of degradation. (F) Stills from $\Delta c s a r 1$ parasites imaged as in (E). Annotations as above; yellow arrows indicate viable daughter conoids at end of division in +IAA media. 


\section{Figure 7}
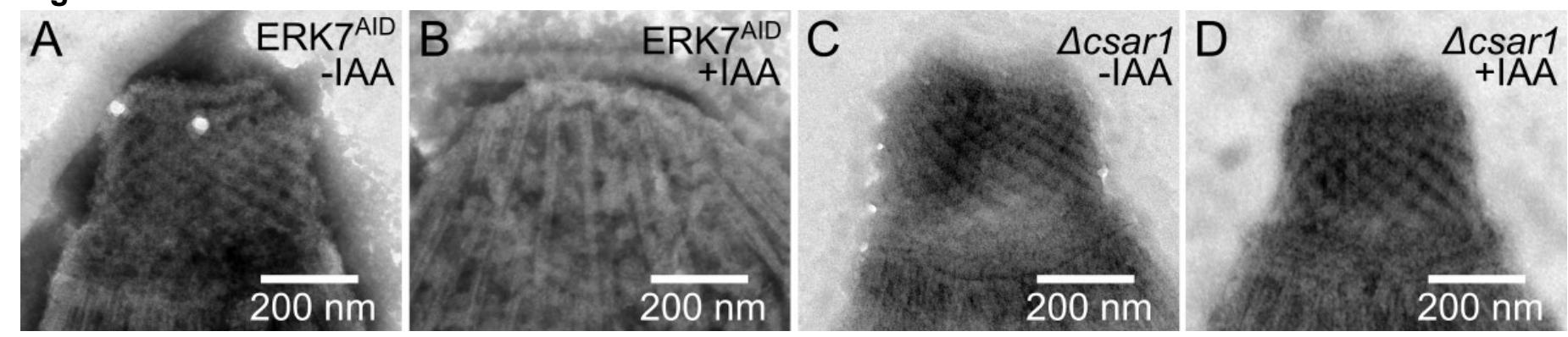

Figure 7: The conoid ultrastructure is preserved in $\Delta c s a r 1$ parasites. Negative-stained TEM of detergent-extracted cytoskeleton "ghosts" from the indicated strains and grown in \pm IAA. 


\section{Figure 8}
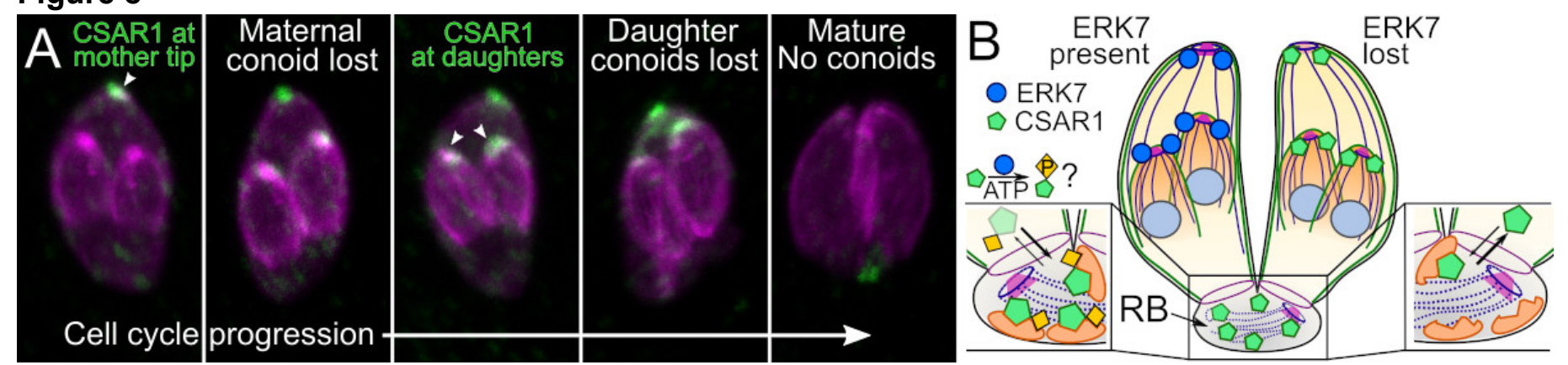

Figure 8: Model of functional relationship between CSAR1 and ERK7. (A) Confocal micrographs of CSAR $1^{3 \times H A}\left(E R K 7^{A I D}\right)$ parasites grown in +IAA for $5 \mathrm{~h}$. CSAR1 signal appears to build up first at the maternal and then at the daughter conoids just before the loss of the structures. (B) In normal parasites, ERK7 concentrates at the apical caps of both maternal and daughter parasites and drives CSAR1 to concentrate in the residual body (RB), possibly through ERK7 kinase activity. This protects the maternal and daughter apical complexes from degradation. When ERK7 is lost, CSAR1 is not retained in the residual body and concentrates at the apical tips of mother and daughter cells, leading to premature degradation of the conoids. 


\section{Supplemental Material}

Candidates from the ERK7 interactome were examined by creating screens in which the gene of interest was expressed in-frame with a C-terminal 3xHA tag in the background of the ERK7 $7^{\text {AID }}$ strain. Parasites were grown in $\pm \mathrm{IAA}$ for $24 \mathrm{~h}$ before fixation. Samples were stained with antibodies recognizing the HA-tag and the indicated counter-stain (usually ISP1, a marker for the apical cap). All images are representative of a minimum of $n=20$ images and are maximum intensity Z-projections of confocal stacks. 
bioRxiv preprint doi: https://doi.org/10.1101/2021.12.09.471932; this version posted December 9, 2021. The copyright holder for this preprint (which was not certified by peer review) is the author/funder, who has granted bioRxiv a license to display the preprint in perpetuity. It is made available under aCC-BY-NC 4.0 International license.
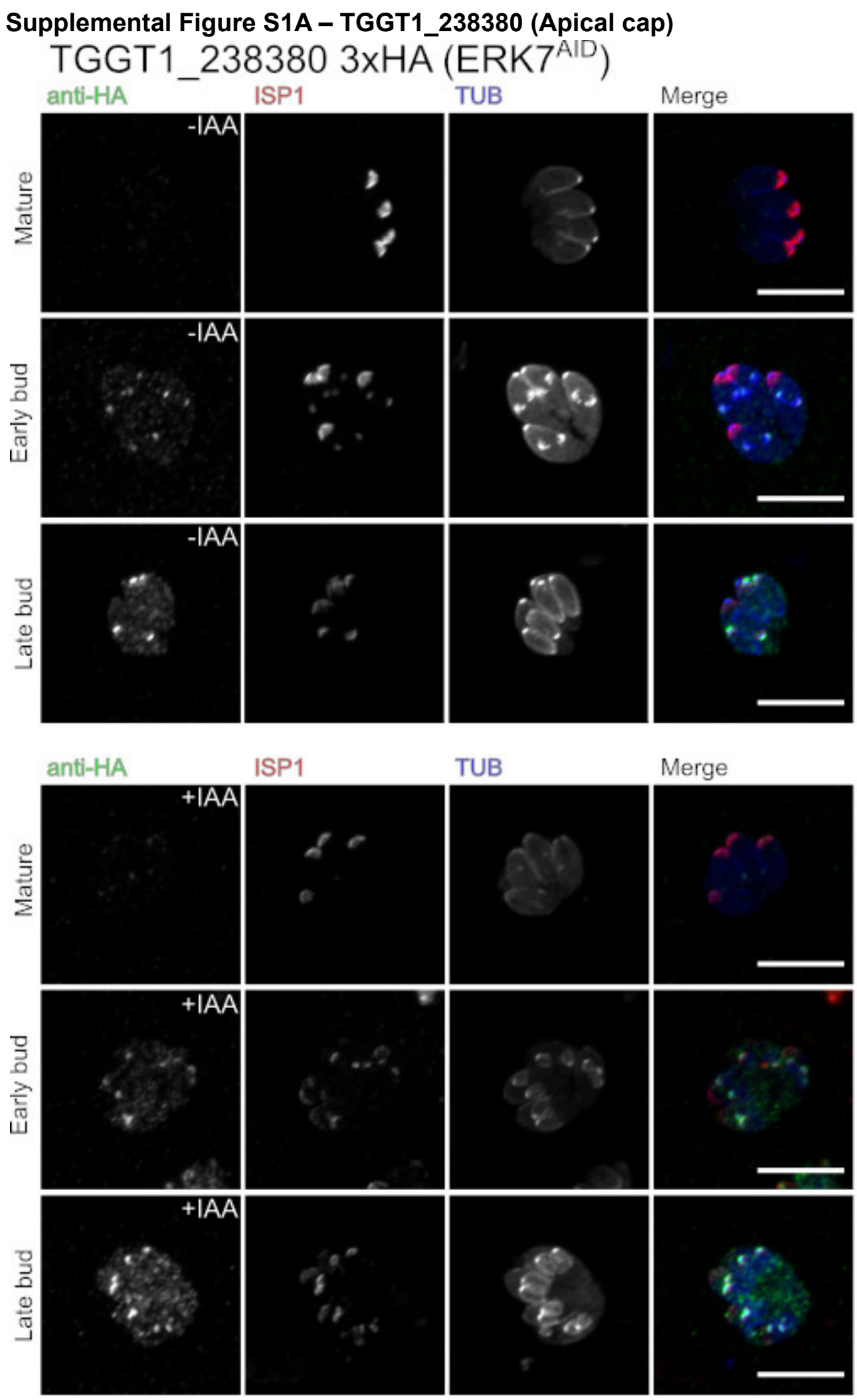
bioRxiv preprint doi: https://doi.org/10.1101/2021.12.09.471932; this version posted December 9, 2021. The copyright holder for this preprint (which was not certified by peer review) is the author/funder, who has granted bioRxiv a license to display the preprint in perpetuity. It is made available under aCC-BY-NC 4.0 International license.

\section{Supplemental Figure S1B - TGGT1_236060 (Concentrated apically) TGGT1_236060 3xHA (ERK7 $\left.7^{\text {AID }}\right)$}
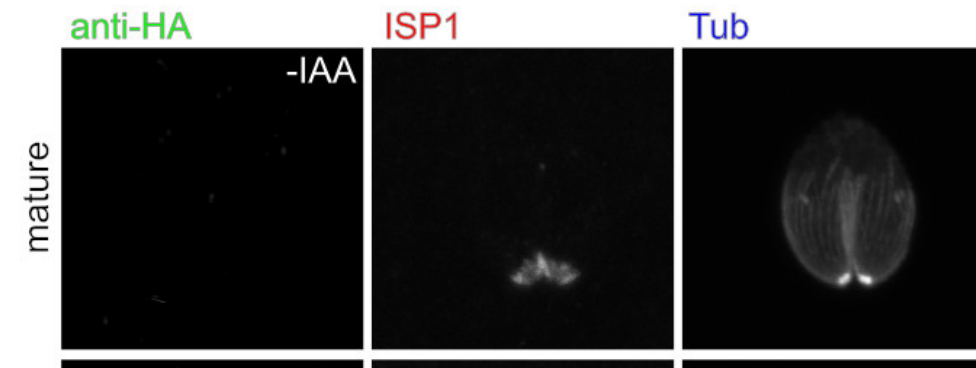

Merge
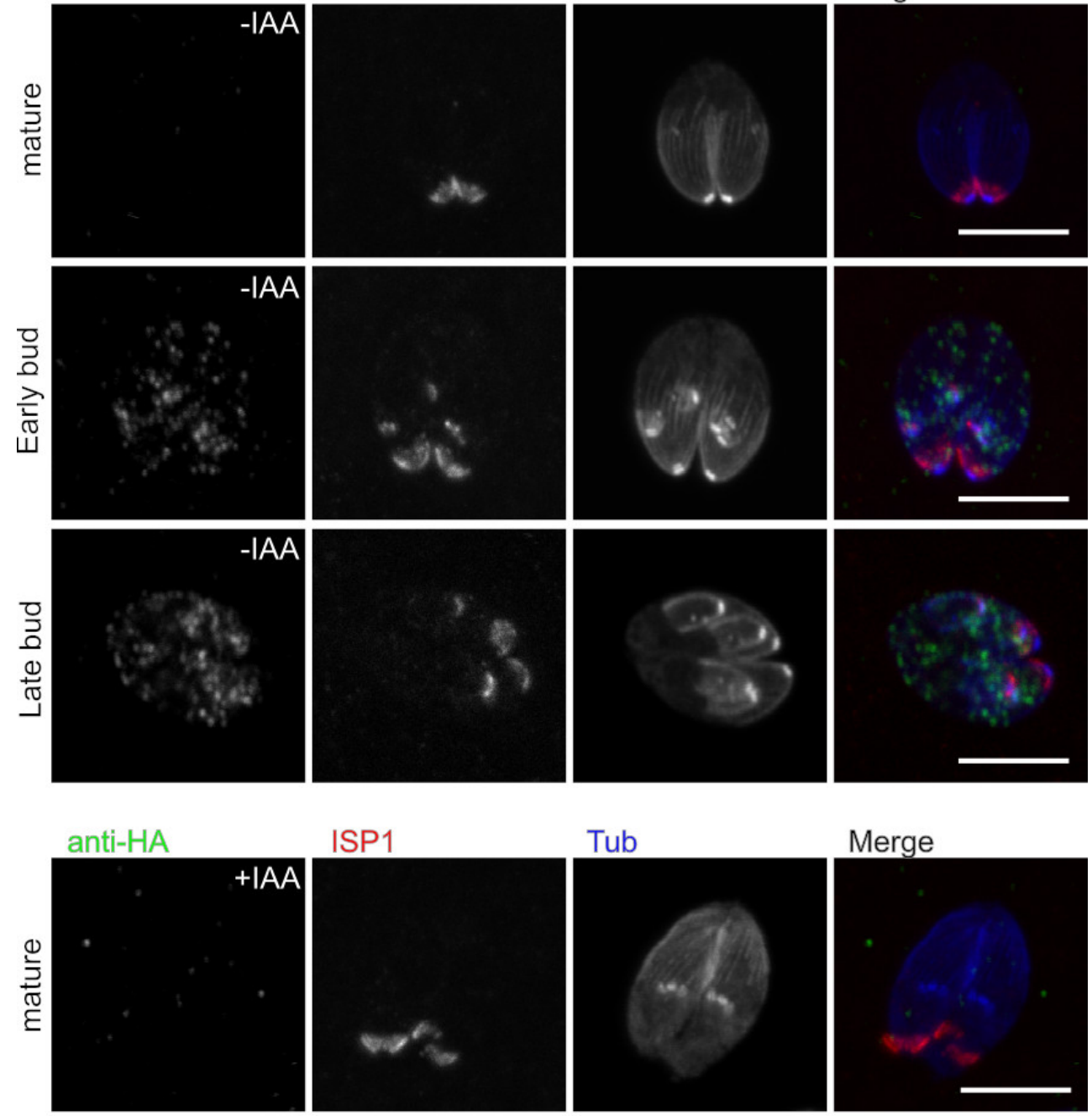

Tub
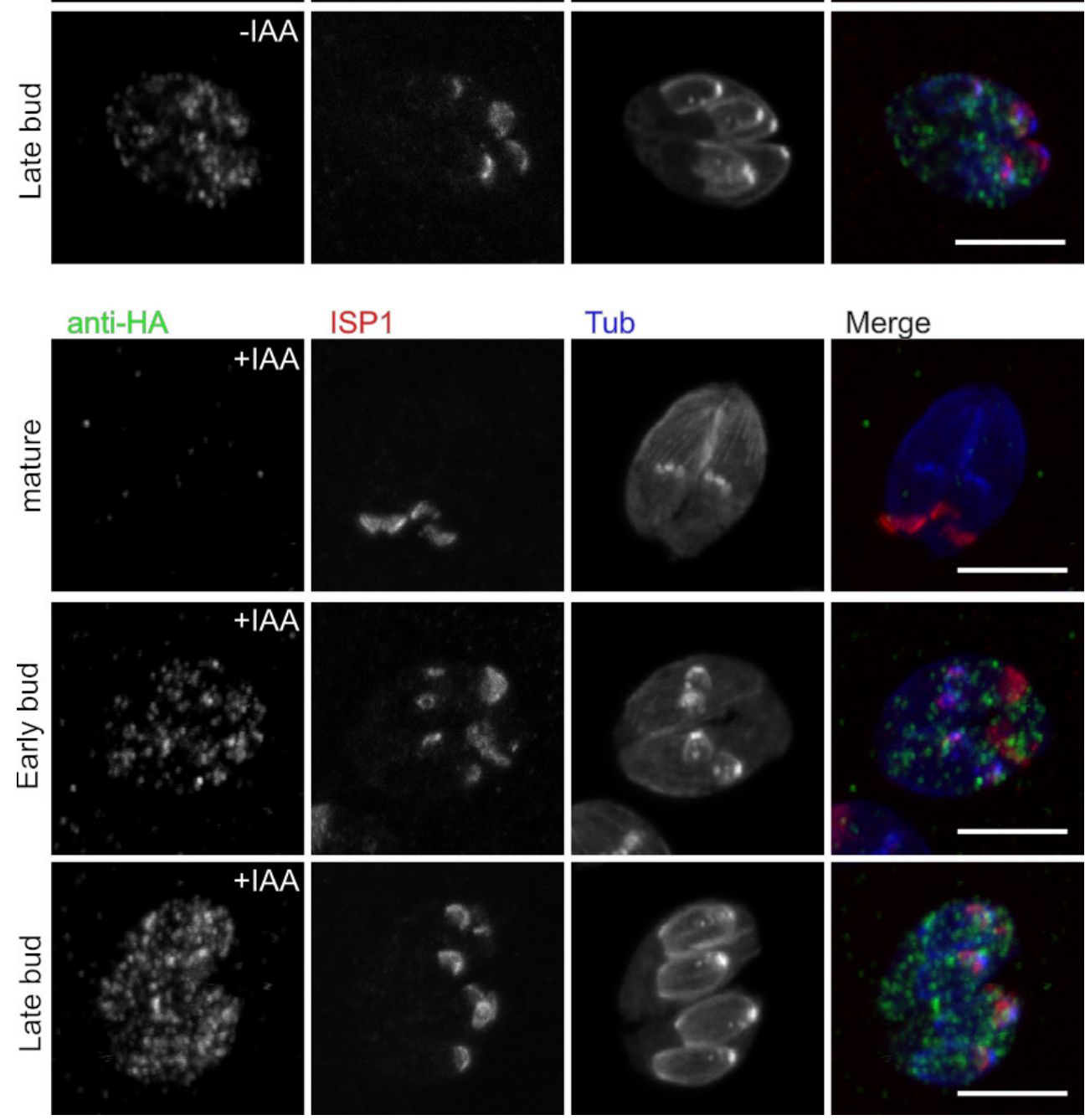

Merge
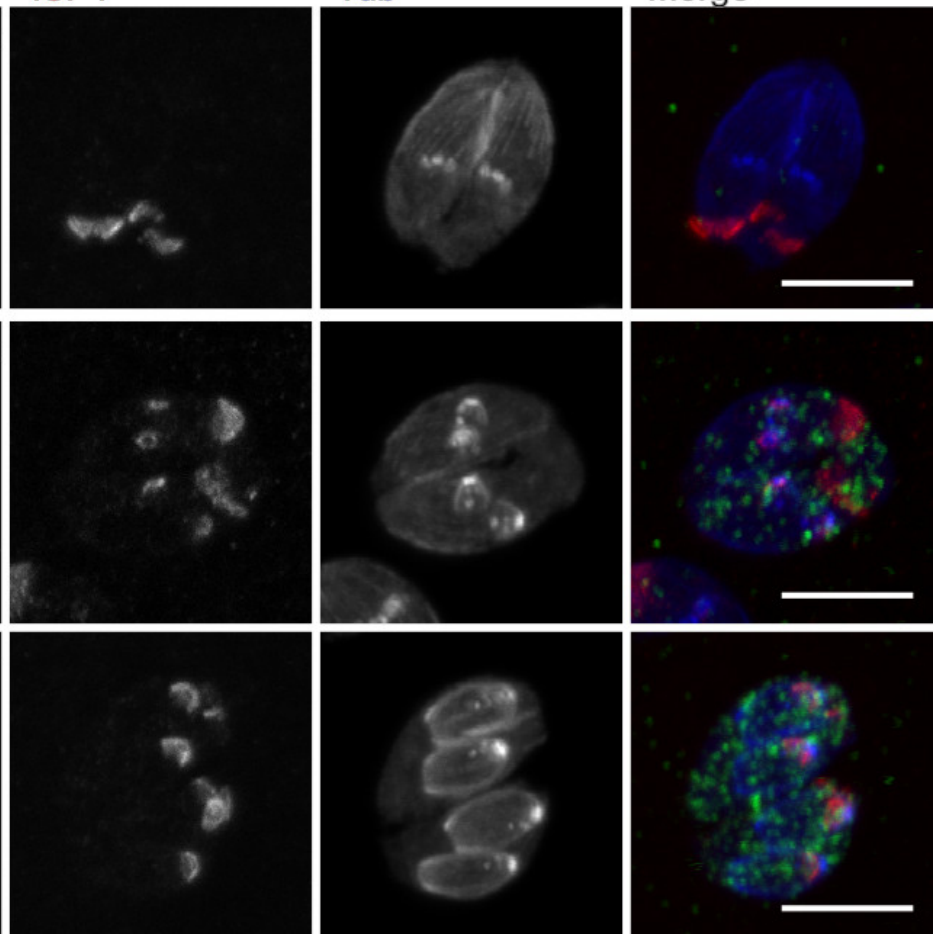
bioRxiv preprint doi: https://doi.org/10.1101/2021.12.09.471932; this version posted December 9, 2021. The copyright holder for this preprint (which was not certified by peer review) is the author/funder, who has granted bioRxiv a license to display the preprint in perpetuity. It is made available under aCC-BY-NC 4.0 International license.

\section{Supplemental Figure S1C - TGGT1_285140 (Apical puncta)}

\section{TGGT1_285140 3xHA (ERK7 ${ }^{\mathrm{AID}}$ )}

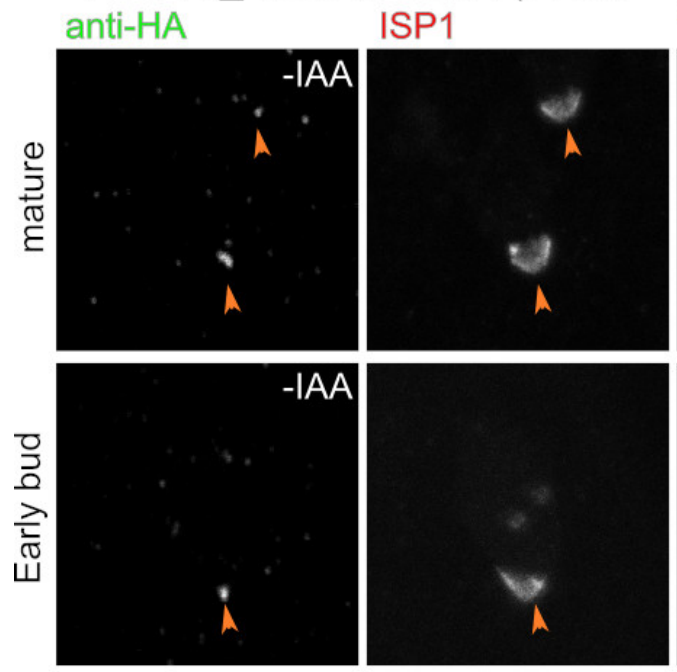
Tub Merge
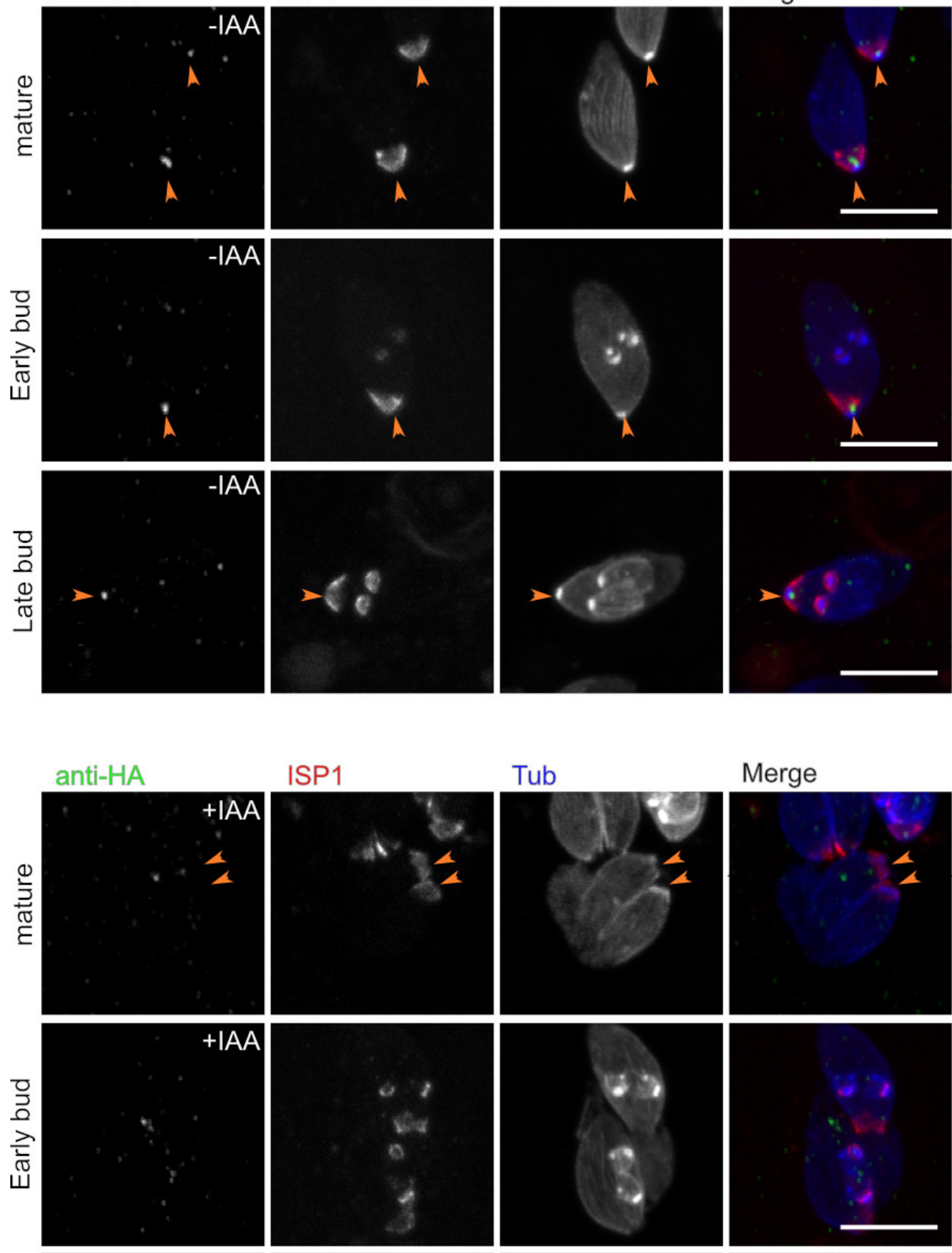

Tub
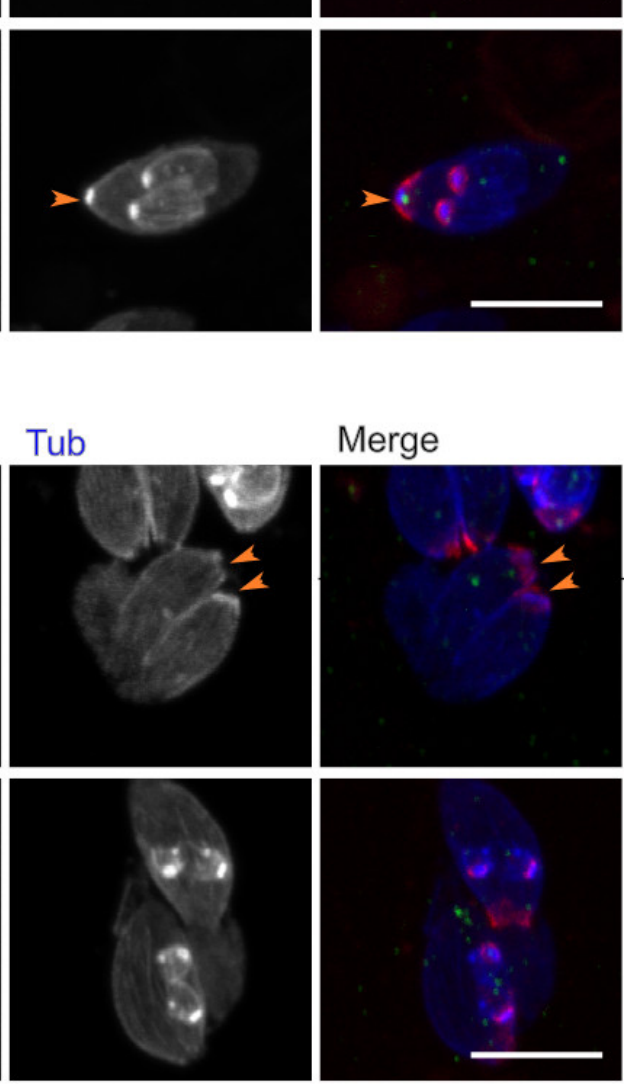

Merge
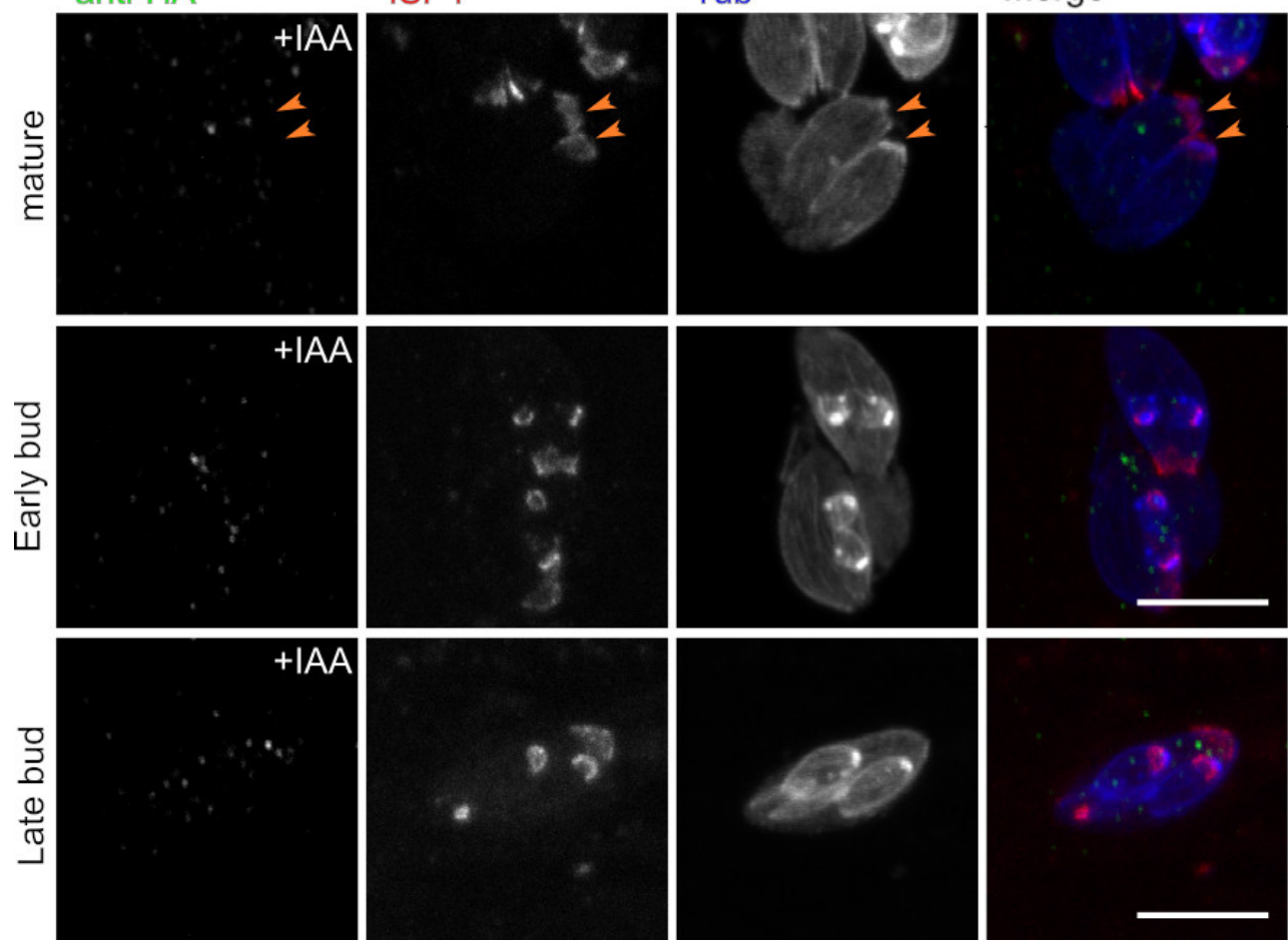
bioRxiv preprint doi: https://doi.org/10.1101/2021.12.09.471932; this version posted December 9, 2021. The copyright holder for this preprint (which was not certified by peer review) is the author/funder, who has granted bioRxiv a license to display the preprint in perpetuity. It is made available under aCC-BY-NC 4.0 International license.

\section{Supplemental Figure S1D - TGGT1_260500 (IMC Sutures)}
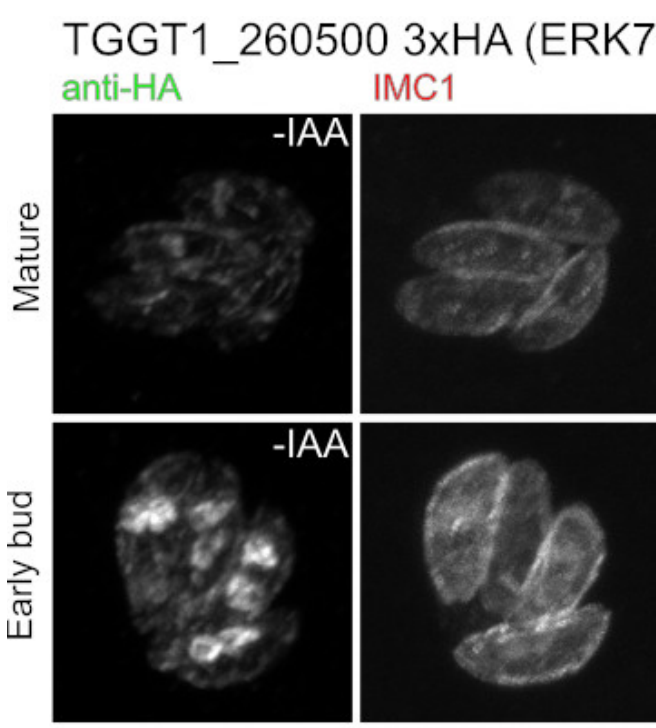

TUB
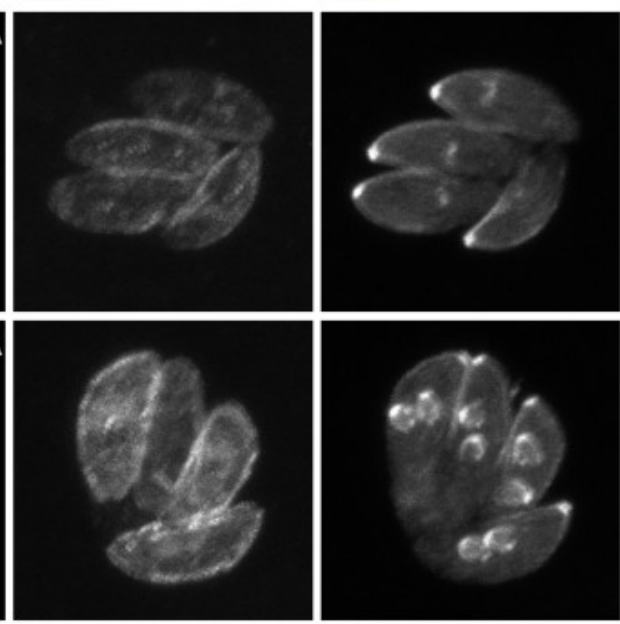

Merge
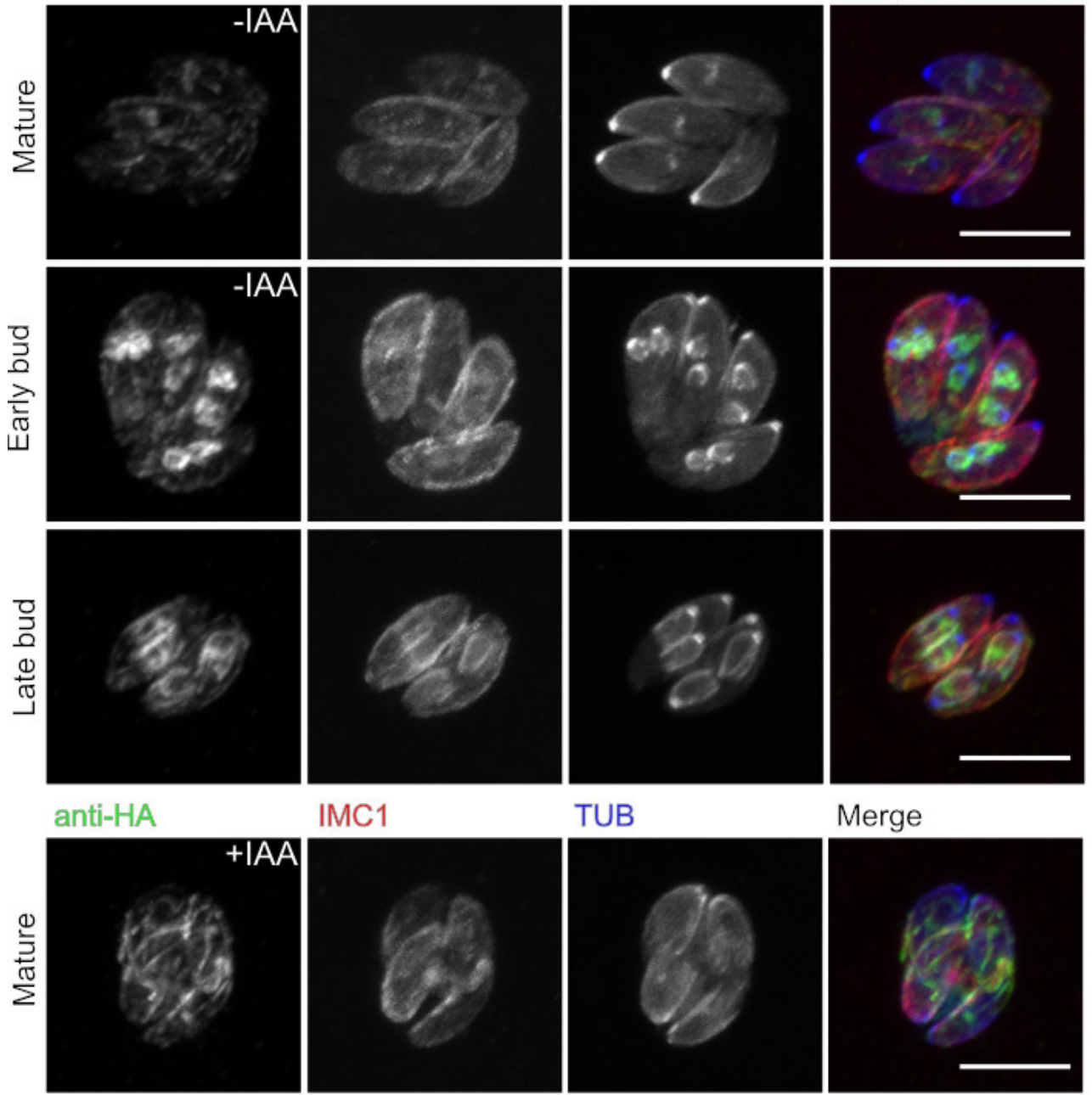

IMC1

TUB
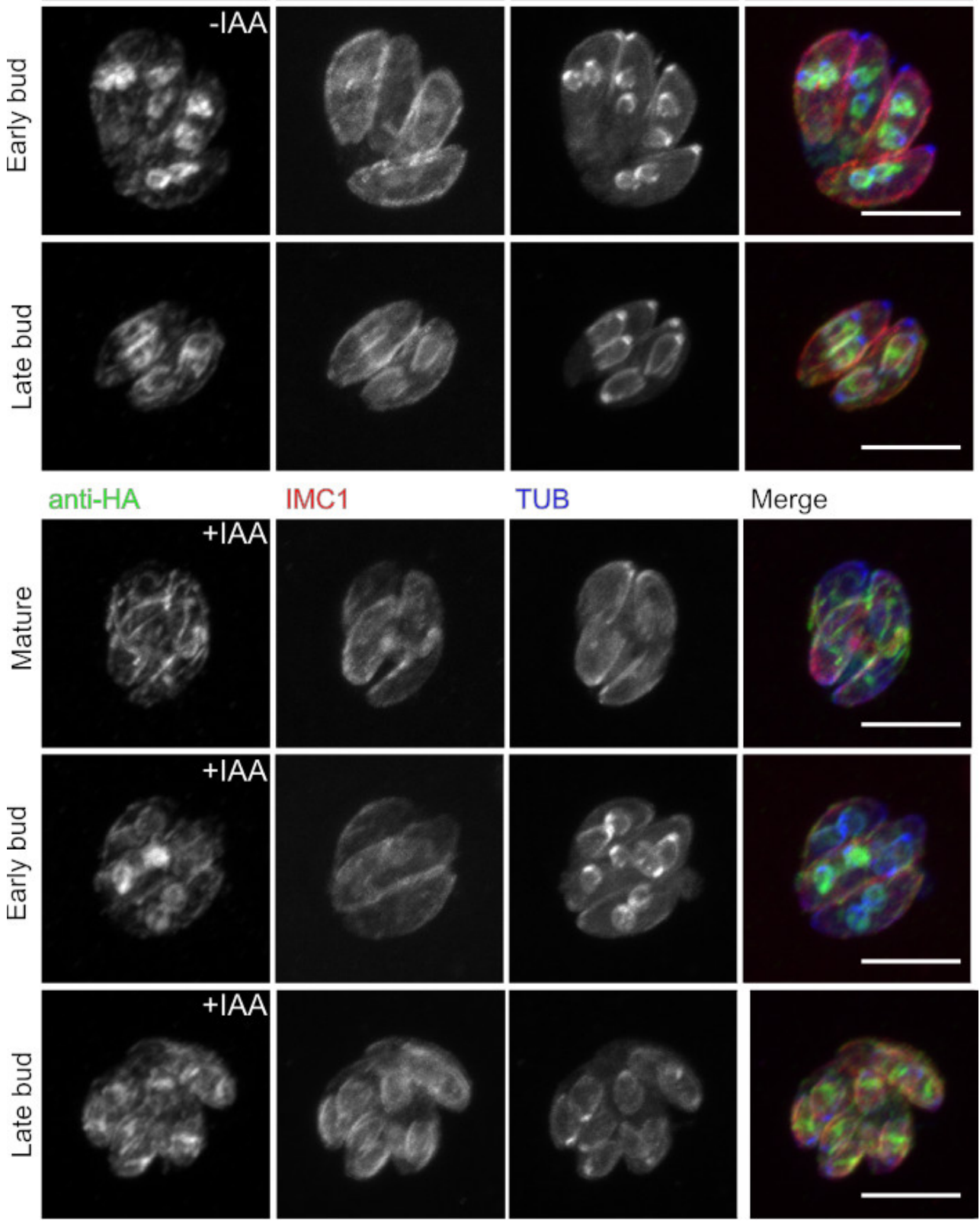

Merge
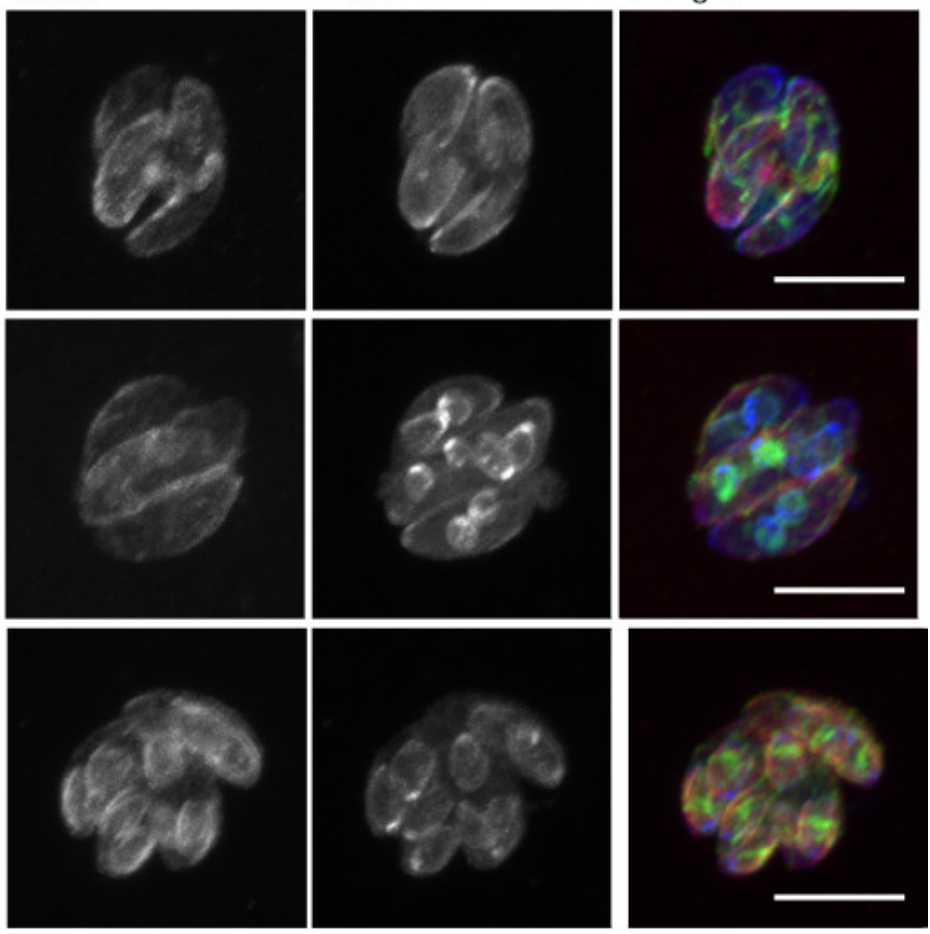
bioRxiv preprint doi: https://doi.org/10.1101/2021.12.09.471932; this version posted December 9, 2021. The copyright holder for this preprint (which was not certified by peer review) is the author/funder, who has granted bioRxiv a license to display the preprint in perpetuity. It is made available under aCC-BY-NC 4.0 International license.

Supplemental Figure S1E - TGGT1_231210 (Potential endolysosomal) TGGT1_231210 3xHA (ERK7 $\left.{ }^{\text {AID }}\right)$
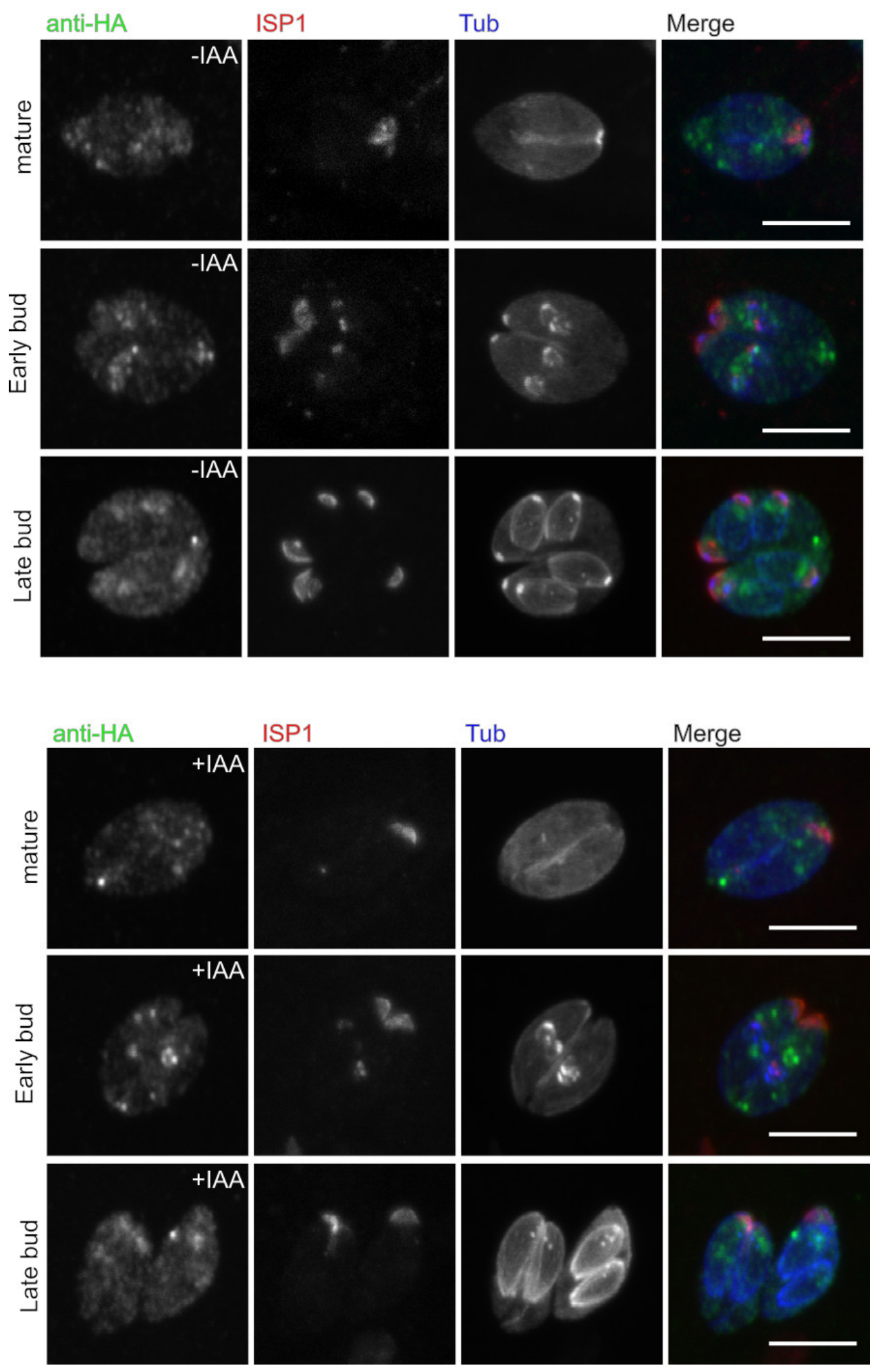
bioRxiv preprint doi: https://doi.org/10.1101/2021.12.09.471932; this version posted December 9, 2021. The copyright holder for this preprint

(which was not certified by peer review) is the author/funder, who has granted bioRxiv a license to display the preprint in perpetuity. It is made available under aCC-BY-NC 4.0 International license.

\section{Supplemental Figure S1F - TGGT1_309560 (Potential endolysosomal)}

TGGT1_309560 3xHA (ERK7 $\left.{ }^{\text {AID }}\right)$
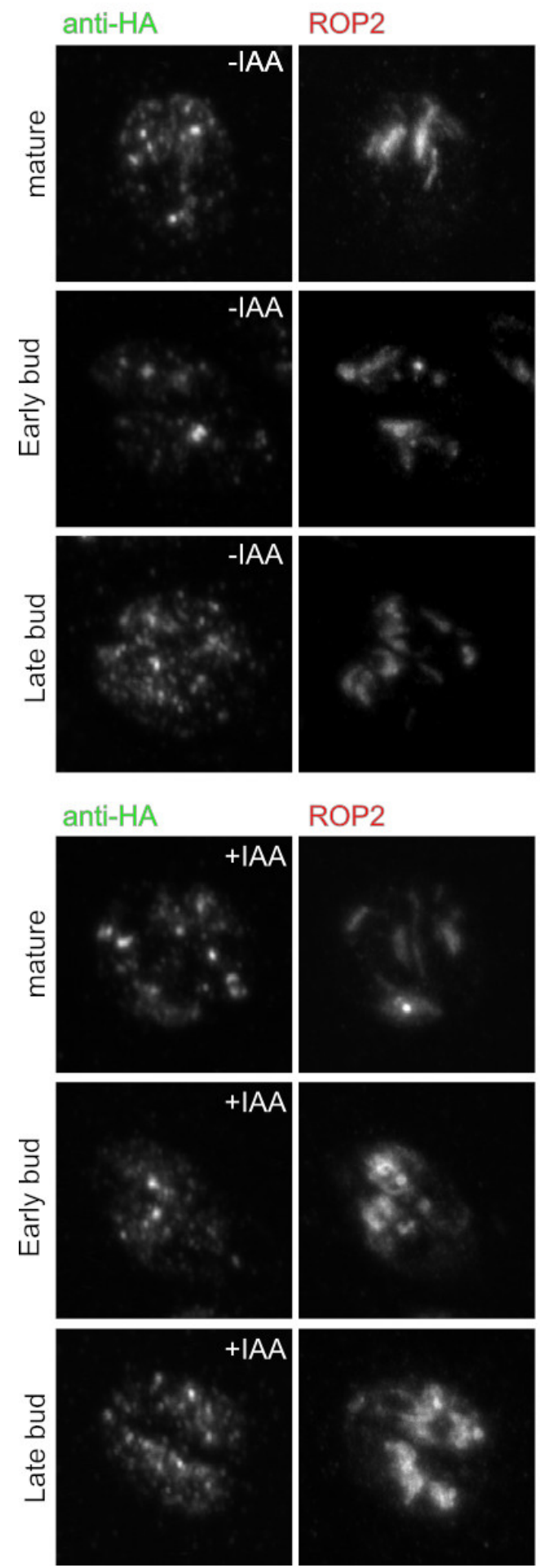

MIC2
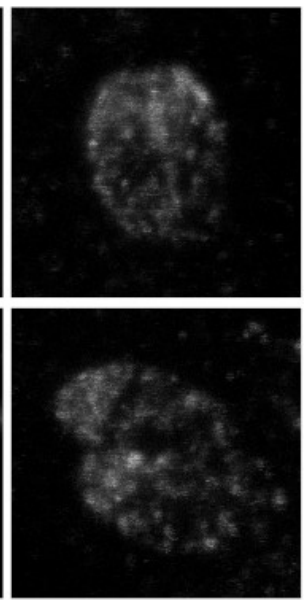

Tublin
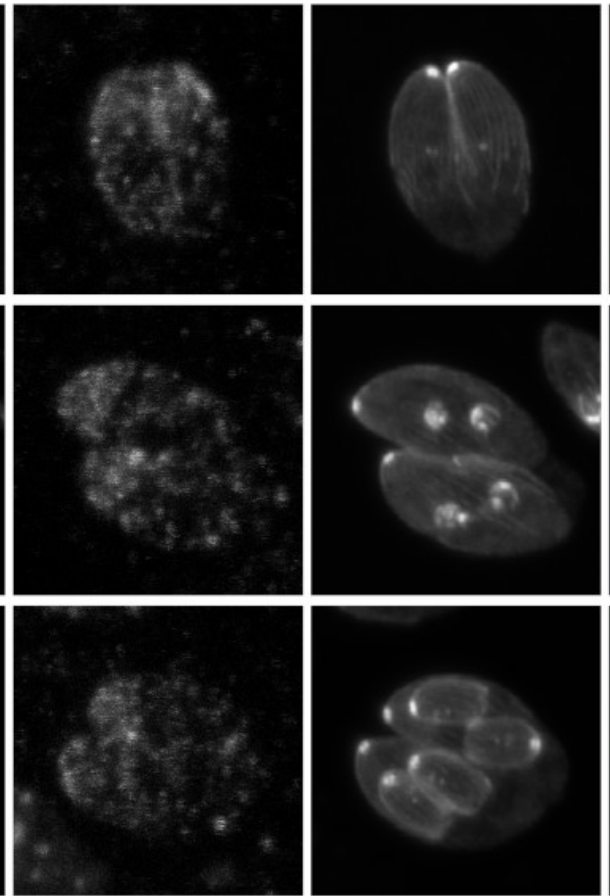

$\mathrm{MIC2}$

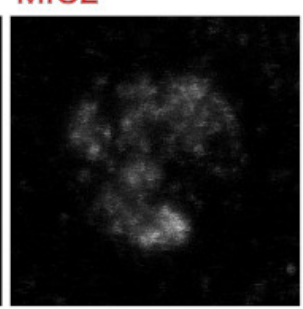

Tublin
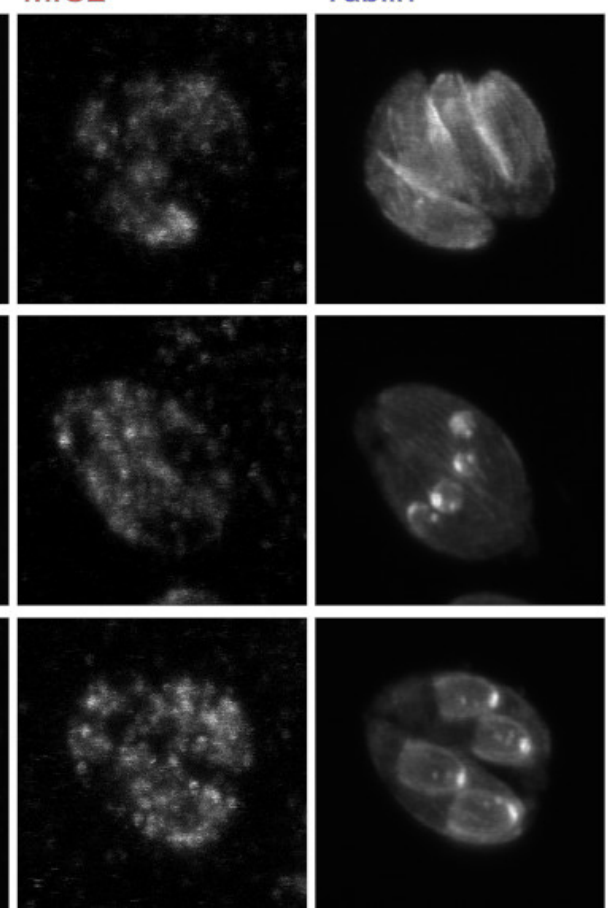

Merge with ROP2 Merge with MIC2
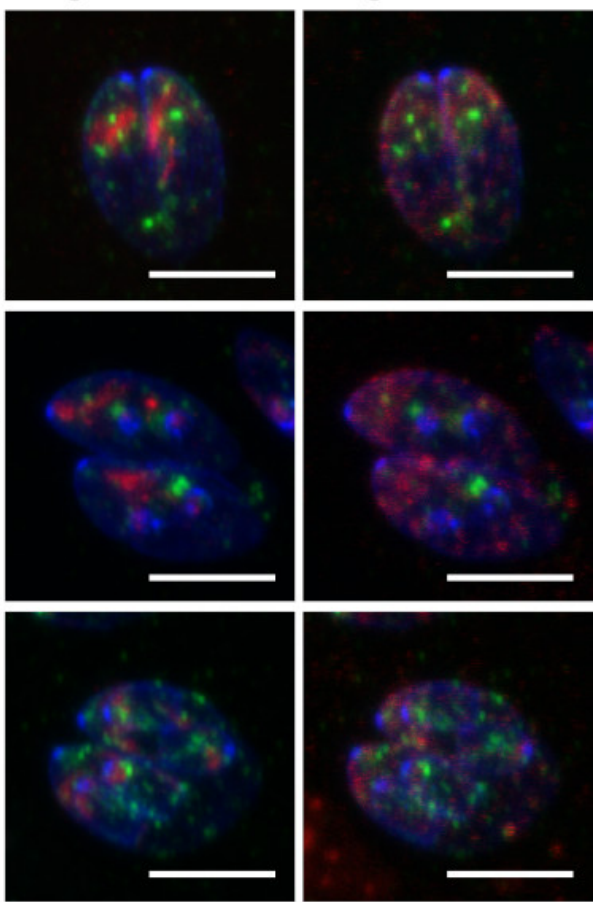

Merge with ROP2 Merge with MIC2
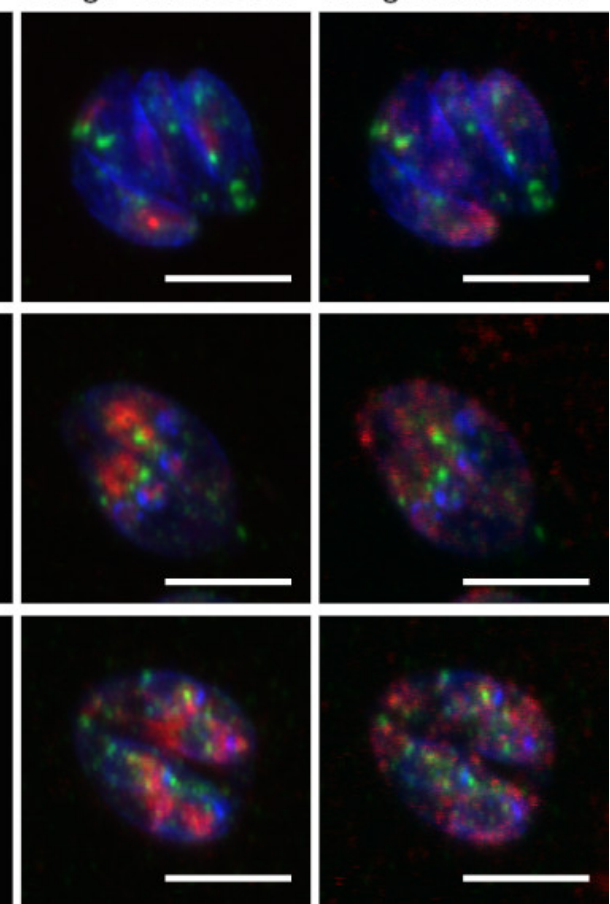


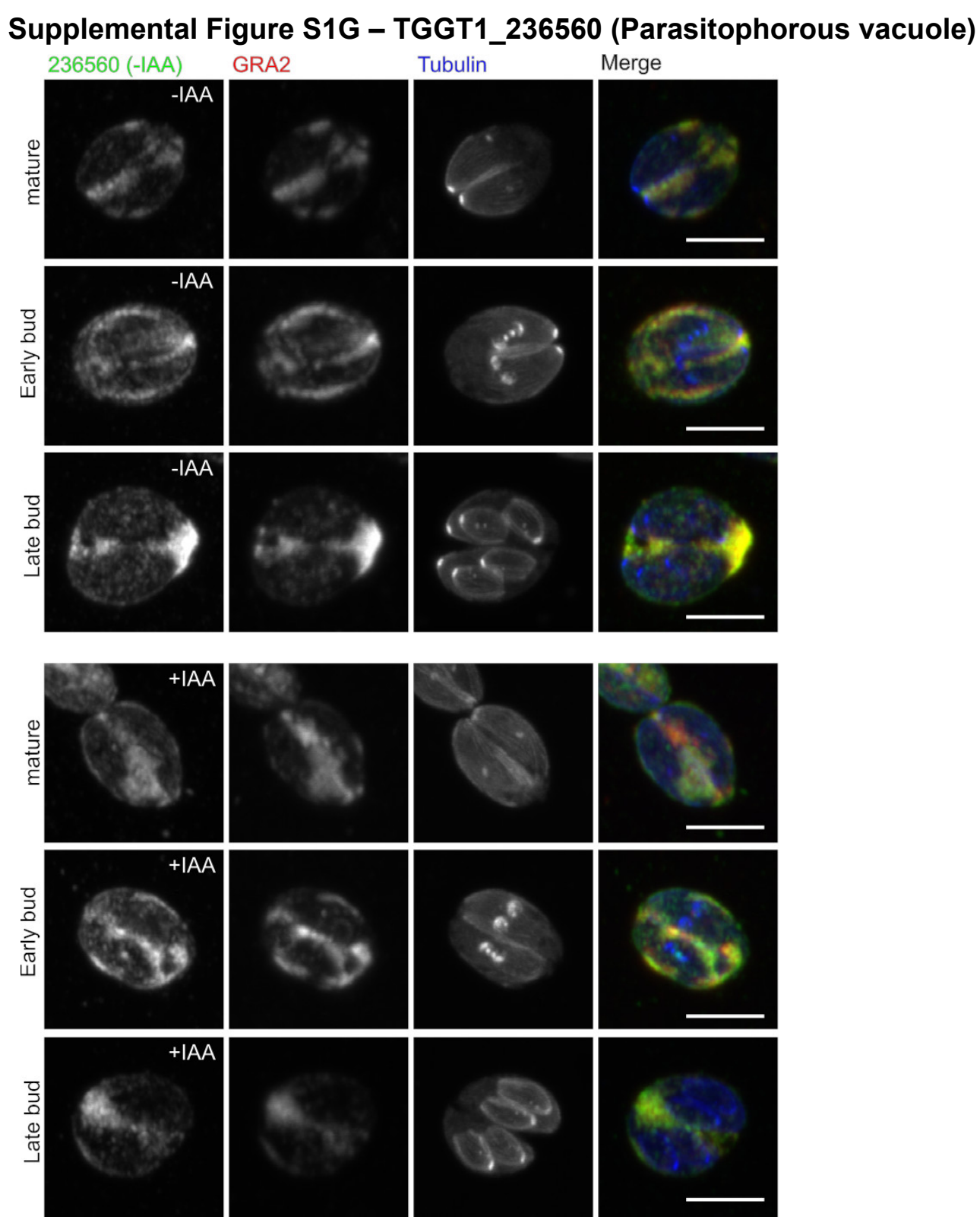

Supplemental Figure S1G: While TGGT1_236560 was a hit in both our Yeast-two-hybrid and BiolD datasets, C-terminal tagging led to vacuole localization, which is inconsistent with an interaction with cytosolic ERK7. TGGT1_236560 also has no predicted signal peptide. Note that the predicted protein length is $\sim 250 \mathrm{kDa}$, and the gene has no predicted introns, which is unusual for a gene of this size. It is therefore possible that the gene model is incorrect and represents a combination of a cytosolic protein (at the 5' end of the gene) and a secreted protein (at the $3^{\prime}$ end). 